\title{
NAVY DEPARTMENT
}

THE DAVID W. TAYLOR MODEL BASIN

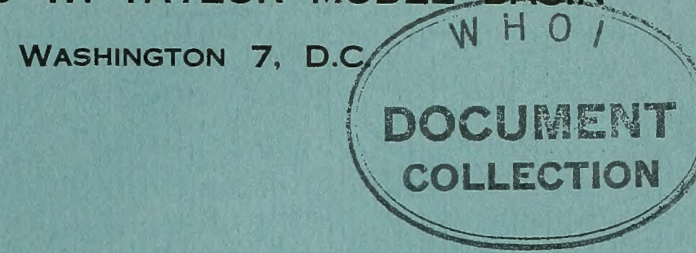

A METHOD FOR THE CALCULATION OF THE

TURBULENT BOUNDARY LAYER IN A PRESSURE GRADIENT

by

Paul S. Granville

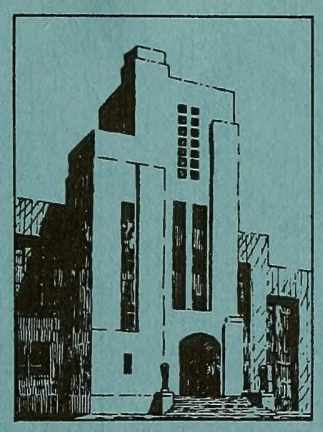

May 1951

Report 752

NS $715-084$

103

no. 752 


\section{INITIAL DISTRIBUTION}

Copies

17 Chief, BuShips, Project Records (Code 324), for distribution:

5 Project Records

3 Research (Code 300)

2 Applied Science (Code 370)

2 Design (Code 470)

2 Preliminary Design (Code 420)

1 Propellers and Shafting (Code 554)

1 Technical Assistant to Chief of the Bureau (Code 106)

1 Submarines (Code 515)

5 Chief, Buord, Underwater Ordnance (Re6a)

1 Dr. A. Miller

3 Chief, BuAer, Aerodynamies and Hydrodynamics Branch (DE-3)

4 Chief of Naval Research, for distribution:

3 Fluid Mechanics (N426)

1 Undersea Warfare (466)

15 Chief of Naval Operations, op $322 \mathrm{~F}$, for distribution:

3 British Ministry of Supply, Washington, D.C.

6 British Joint Services Mission, Washington, D.C., 4 for Navy Staff and 2 for Technical Staff

1 Superintendent, Admiralty Research Laboratory, Teddington, Middlesex, England

2 Australian Scientific Research Liaison Office, Washington, D.C.

3 Hydrodynamics Laboratory, National Research Laboratory, Ottawa, Canada

4 Commander, U.S. Naval Ordnance Laboratory, Mechanics Division, White Oak, Silver Spring 19, Md., 1 for Dr. Max Munk

Commander, Naval Ordnance Test Station, Inyokern, China Lake, Calif., 1 for Underwater Ordnance Division, Pasadena

Commanding Officer, Navy Underwater Sound Laboratory, Fort Trumbull, New London, Conn.

Commanding Officer, Naval Torpedo Station, Design Section, Newport, R.I.

Director, National Advisory Committee for Aeronautics, 1724 F St., N.W., Washington, D.C.

Mr. N. Tetervin, Langley Memorial Aeronautical Laboratory, Langley Air Force Base, Va.

Commander, Portsmouth Naval Shipyard, Portsmouth, N.H., Attn: Design Superintendent

Director, Woods Hole Oceanographic Institution, Woods Hole, Mass.

Newport News Shipbuilding and Dry Dock Co., Newport News, Va., for distribution:

1 Senior Naval Architect

1 Supervisor, Hydraulics Laboratory

Director, Experimental Towing Tank, Stevens Institute of Technology, 711 Hudson Street, Hoboken, N.J.

Dr. Hunter Rouse, Director, Iowa Institute of Hydraulic Research, State University of Iowa, Iowa City, Iowa 
2 Director, Ordnance Research Laboratory, Pennsylvania State College, State College, $\mathrm{Pa}$.

Dr. R.T. Knapp, Director, Hydrodynamic Laboratory, California Institute of Technology, Pasadena 4, Calif.

Dr. I.G. Straub, Director, St. Anthony Falls Hydraulic Laboratory, University of Minnesota, Minneapolis 14, Minn.

Director, Experimental Naval Tank, Department of Naval Architecture and Marine Engineering, University of Michigan, Ann Arbor, Mich.

Dr. V.L. Streeter, Illinois Institute of Technology, 3300 Federal Street, Chicago 16, Ill.

Head, Department of Naval Architecture and Marine Engineering, Massachusetts Institute of Technology, Cambridge 39, Mass.

Dr. C.C. Lin, Department of Mathematics, Massachusetts Institute of Technology, Cambridge 39, Mass.

Director, Applied Physics Laboratory, Johns Hopkins University, 8621 Georgia Avenue, Silver Spring, Md.

Prof. W. S. Hamilton, Technical Institute, Northwestern University, Evanston, Ill.

Prof. G. Birkhoff, Harvard University, Cambridge, Mass.

Prof. K.E. Schoenherr, School of Engineering, Notre Dame University, South Bend, Ind.

Prof. W. Spannhake, Armour Research Foundation, 35 West 33rd Street, Chicago 16, Ill.

Dr. W. Pell, Division of Applied Mathematics, Brown University, Providence, R.I.

Dr. J.V. Wehausen, Editor, Mathematical Reviews, Providence, R.I.

Dr. C.H. Lee, U.S. Naval Postgraduate School, Annapolis, Md.

Prof. C. Yih, Department of Civil Engineering, Colorado A and $M$ College, Fort Collins, Colo.

Dr. D. Gilbarg, Department of Mathematics, Indiana University, Bloomington, Ind.

Prof. J. Vennard, Department of Civil Engineering, Stanford University, Palo Alto, Calif.

Prof. B.A. Bakhmeteff, Department of Civil Engineering, Columbia University, New York 27, N.Y.

Dr. G.F. Wislicenus, Mechanical Engineering Department, Johns Hopkins University, Baltimore 18, Md.

Librarian, American Society of Mechanical Engineers, 29 West 39th St. , New York 18, New York

Librarian, American Society of Civil Engineers, 33 West 39th St., New York 18, N.Y.

Director, U.S. Waterways Experiment Station, Vicksburg, Miss.

Dr. G.B. Schubauer, National Bureau of Standards, Washington, D.C.

Director, Institute for Fluid Dynamics and Applied Mathematics, University of Maryland, College Park, Md., T for Dr. Weinstein 
Prof. R.A. Dodge, Englneering Mechanics Department, University of Michigan, Ann Arbor, Mich.

Editor, Applied Mechanics Reviews, Midwest Beseerch Institute, 4049 Pennsylvania, Kansas City 2, Mo.

Editor, Aeronautical Engineering Review, 2 East 64 th St., New York 21, N.Y.

Editor, Bibliography of Technical Reports, Office of Technical Services, U.S. Department of Commerce, Washington 25, D.C.

Editor, Technical Data Digest, Central Air Documents office, WrightPatterson Air Force Base, Dayton, Ohio

Dr. A.T. Ippen, Director, Hydrodynamics Laboratory, Department of Civil and Sanitary Engineering, Massachusetts Institute of Technology, Cambridge 39, Mass.

Director, Institute for Mathematics and Mechanics, New York University, 45 Fourth Ave., New York 3, N.Y.

Dr. C.A. Wright, Department of Hydraulic and Sanitary Engineering, Polytechnic Institute of Brooklyn, 99 Livingston St., Brooklyn 2, N.Y.

Prof. R.G. Folsom, Department of Engineering, University of California, Berkeley 4, Calif.

Prof. C.W. Harris, Department of Civil Engineering, University of Washington, Seattle 5, Wash.

Prof. S.A. Guerrieri, Division of Chemical Engineering, University of Delaware, Newark, Del.

Dr. V.G. Szebehely, Hydraulic Laboratory, Virginia Polytechnic Institute, Blacksburg, Va.

Prof. J.L. Hooper, Alden Hydraulic Laboratory, Worcester Polytechnic Institute, Worcester, Mass.

Director, Technical Information Branch, Aberdeen Proving Grounds, Aberdeen, Md.

Goodyear Aircraft Corporation, Akron, Ohio

Librarian, Daniel Guggenheim Aeronautical Laboratory, California Institute of Technology, Pasadena 4, Calif.

Director, Institute of Aeronautical Sciences, 2 East 64 th St., New York 21, N.Y.

Librarian, College of Engineering, Cornell University, Ithaca, N.Y.

1 . Librarian; Carnegie Institute of Technology, Pittsburgh $13, \mathrm{~Pa}$.

Librarian, Case Institute of Technology, Cleveland 6, Ohio

Librarian, Illinois Institute of Technology, 3300 Federal St., Chicago 16, IIl.

Librarian, Rensselear Polytechnic Institute, Troy, N.Y.

Librarian, Franklin Institute, Parkway at 20th St., Philadelphia, Pa. 
1 Librarian, Pacific Aeronautical Library, Institute of the Aeronautical Sciences, 7660 Beverly Blvd., Los Angeles 36, Calif.

Head, Aeronautical Engineering Department, Catholic University, Washington, D.C.

Head, Technical Reference Section, U.S. Department of Interior, Bureau of Reclamation, Denver Federal Center, Denver, Colo.

Chairman, Department of Aeronautical Engineering, New York University, University Heights, New York 53, N.Y.

BAR, Cornell Aeronautical Laboratory, Cornell Research Foundation, Box 235, Buffalo 21, N.Y.

BAR, Pratt and Whitney Aircraft Division, United Aircraft Corp., East Hartford 8, Conn.

BAR, North American Aviation, Inc., 12241 Lakewood Blvd., Downey, Calif.

BAR, McDonnell Aircraft Corp., Box 516, St. Louis 3, Mo.

BAR, Glenn L. Martin Co., Baltimore 3, Md.

BAR, East Akron Station, Akron 5, Ohio

BAR, Lockheed Aircraft Corp., 2555 North Hollywood Way, Burbank, Calif.

BAR, Consolidated Vultee Aircraft Corp., San Diego 12, Calif.

BAR, North American Aviation, Inc., Columbus Division, 4300 East 5 th Ave., Columbus, Ohio

BAR, Douglas Alrcraft Co., Inc., El Segundo, Calif.

BAR, Grumann Aircraft Engineering Corp., Bethpage, Long Island, N.Y. Dr. Th. von Kármán, 1051 South Marengo St., Pasadena, Cal1f.

Prof. A.D. Hay, Princeton University, Princeton, N.J.

Administrator, Webb Institute of Naval Architecture, Crescent Beach Road, Glen Cove, Long Island, N.Y.

Prof. R.C. Binder, Department of Mechanical Engineering, Purdue University, Lafayette, Ind.

Dr. M.S. Plesset, California Institute of Technology, Pasadena 4, Calif.

Dr. A.G. Strandhagen, School of Engineering, Notre Dame University, South Bend, Ind.

Prof. M.H. Martin, Head of Mathematics Department, University of Maryland, College Park, Má.

Dr. W. Douglas Baines, Department of Clvil Engineering, Michigan State College, East Lansing, Mich.

Dr. V.L. Schiff, Stanford University, Palo Alto, Calif.

Mr. C.A. Lee, Hydraulic Engineer, Research and Development Laboratories, Kimberly-Clark Corp., Neenah, Wis.

Prof. J.K. Lunde, Skipsmodelltanken, Tyholt Trondheim, Norway

Prof. L. Troost, Superintendent, Netherlands Ship Model Basin, Haagsteeg 2, Wageningen, The Netherlands 
Copies

1 Directeur' du Bassin d'Essais Des Carènes, 5, Boulevard Victor, Paris XV, France

Director, Swedish State Shipbuilding Experimental Tank, Göteborg 24 , Sweden

Dr. G. Hughes, National Physical Laboratory, Teddington, Middlesex, England

Editor, Journal of the British Shipbuilding Research Association, 5, Chesterfield Gardens, Curzon St., London W. 1, England

Editor, Physics Abstracts, Institution of Electrical Engineers, Savoy Place, London W.C. 2, England

Editor, Index Aeronauticus, Ministry of Supply, Millbank, London S.W. 1, England

Head, Aerodynamics Department, Royal Aircraft Establishment, Farnborough, Hants, England

Head, Aerodynamics Division, National Physical Laboratory, Teddington, Middlesex, England

Head, Aeronautics Department, Imperial College, London, S.W. 7 , England

Head, College of Aeronautics, Cranfleld, Bletchley, Bucks, England

Prof. J. Kampé de Fériet, Faculté des Sciences, Université de Lille, Lille (Nord), France

1 Directeur, Laboratolre Dauphinois d'Hydraulique des Ateliers Neyrpic, Avenue de Beauvert, Grenoble (Isère), France

1 Office National d'Études et de Recherches Aéronautiques 3, rue Léon Bonnat, Paris XVI, France

1 Prof. D.P. Riabouchinsky, Centre National de la Recherche Scientifique, 13 Qua1 d'Orsay, Paris VII, France

1 Prof. J.M. Burgers, Laboratorium Voor Aero-En Hydrodynamica, Nieuwe Laan 76, Delft, The Netherlands

1 Dr. R. Timman, National Luchtvaartlaboratorium, Sloterwag 145 , Amsterdam, The Netherlands

1 Director, Aeronautical Research Institute of Sweden, Ranhammarsvagen 12, Ulsvunda, Sweden

1 Prof. J. Ackeret, Institut für Aerodynamik Der Eidgenössiche Technische Hochschule, Zürich, Switzerland

Dr. L. Malavard, Office National d'Études et de Recherches Aéronautiques, Chatillon, Paris, France 

TABLE OF CONTENTS

Page

ABSTRACT . . . . . . . . . . . . . . . . . . . 1

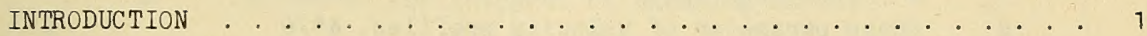

FUNDAMENTAL RELATIONS FOR TURBULENT BOUNDARY LAYERS . . . . . . . . 2

EXISTING METHODS FOR CALCULATING TURBULENT BOUNDARY LAYERS IN A

PRESSURE GRADIINT . . . . . . . . . . . . . . . . . . . . . . . . . . . 7

LOCAL SKIN FRICTION AS A FUNCTION OF PRESSURE GRADIENT . . . . . . . 15

LOCAL-SKLN-FRICTION CUEFFICIENTS FOR FLAT PLATES AT ZERO PRESSURE

GRADIENT . . . . . . . . . . . . . . . . . . . . 20

INTEGRAL OF THE SHEARING-STRESS DISTRIBUTION ACROSS THE BOUNDARY LAYER. 25

MODIFIED MOMENTUM AND MOMENT-OF-MOMENTUM EQUATIONS . . . . . . . . 31

SUMMARY OF METHOD OF CALCULATING TURBULENT BOUNDARY LAYERS IN A

PRESSURE GRADIENT . . . . . . . . . . . . . . . . . . 35

ACKNOWLEDGMENTS . . . . . . . . . . . . . . . . . 37

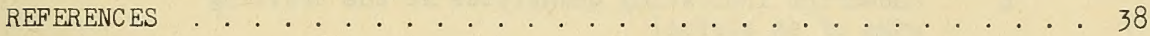


NOTATION

A Coefficient in general auxillary equation, Equation [84]

a Constant in Equation [19]

B Coefficient in general auxiliary equation, Equation [84]

b Constant in Equation [19]

C Constant

$C_{f} \quad$ Drag coefficient, $D / \frac{1}{2} \rho U^{2} S$

D Drag

E Function of $\mathrm{H}$ in Table 3

e Base of natural logarithms

$\mathrm{H}$ Shape parameter of velocity profiles, $\delta^{*} / \theta$

I Shearing-stress distribution integral, $\int_{0}^{1} \frac{\tau}{T_{W}} \mathrm{~d}\left(\frac{\mathrm{y}}{\delta}\right)$

$i$ Subscript referring to initial conditions

$\mathrm{n}$ Exponent of power law for velocity profiles, Equation [8]

- Subscript for flat-plate quantities

$p \quad$ Pressure in fluid

q Exponent in Equation [62]

$\mathrm{R}_{\mathrm{X}}$ Reynolds number based on $\mathrm{x}, \mathrm{Ux} / \nu$

$R_{\theta} \quad$ Reynolds number based on $\theta, \mathrm{U} \theta / \nu$

$r_{W}$ Transverse radius to surface of body of revolution

S Surface area

s Constant in Equation [26]

$t$ Subscript indicating quantities at the trailing edge of an airfoil

U Velocity at outer edge of boundary layer

$U_{\infty} \quad$ Undisturbed velocity of fluid

u Velocity in boundary layer parallel to surface

$u_{\tau}$ Friction velocity, $\sqrt{T_{W} / \rho}$

$v$ Velocity in boundary layer normal to surface

W Width

$x \quad$ Coordinate parallel to surface

y Coordinate normal to surface

$\alpha \quad$ Pressure-gradient parameter, $\frac{\delta}{\tau_{w}} \frac{\mathrm{dp}}{\mathrm{dx}}$

$\beta \quad$ Shearing-stress parameter, $\frac{T_{w_{i}}}{T_{w}} \frac{\delta}{\delta_{i}}$

$\Gamma \quad$ Buri pressure-gradient parameter, $\frac{\theta}{\mathrm{U}} \frac{\mathrm{dU}}{\mathrm{dx}} \mathrm{R}_{\theta}^{1 / 4}$ 
$\gamma \quad$ Velocity parameter, $\left(\frac{u}{\mathrm{~J}}\right)_{\mathrm{y}=\theta}$

$\delta \quad$ Thickness of boundary layer

$\delta^{*} \quad$ Displacement thickness of boundary layer, $\int_{0}^{\delta}\left(1-\frac{\mathrm{u}}{\mathrm{U}}\right) \mathrm{dy}$

$\zeta \quad$ Buri skin-friction parameter

$\eta \quad$ Gruschwitz velocity profile shape parameter, $1-\gamma^{2}$

$\theta$ Momentum thickness of boundary layer, $\int_{0}^{\delta} \frac{u}{U}\left(1-\frac{u}{U}\right) d y$

$\nu \quad$ Kinematic viscosity of fluid

$\rho$ Density of fluid

$\tau \quad$ Shearing stress

$\boldsymbol{\tau}_{w} \quad$ Shearing stress at wall

$\psi \quad$ Parameter for integral of shearing-stress

distribution, $\int_{0}^{\delta / \delta^{*}} \frac{T}{\rho U^{2}} d\left(\frac{y}{\delta^{*}}\right)$ 



\title{
A METHOD FOR THE CALCULATION OF THE TURBULENT BOUNDARY LAYER
}

\section{IN A PRESSURE GRADIENT}

\section{by}

Paul S. Granville

\begin{abstract}
A method is described for the calculation of the development of incompressible turbulent boundary layers in pressure gradients, so that drag and separation of flow may be predicted more accurately. The principal contribution is the formulation of new relations for the variation with pressure gradient of 1 , the shearing stress at the wall (local skin friction) and of 2 , the integral of the shearing stresses across the boundary layer for use in a moment-of-momentum equation recently derived by Tetervin and Lin.
\end{abstract}

With the assumption of the one-parameter characterization of velocity profiles by a shape parameter $\mathrm{H}$, the moment-of-momentum equation and the von Kármán momentum equation constitute a working method involving the solution of a pair of simultaneous first-order differential equations.

As an introduction to the subject of turbulent boundary layers in pressure gradients, a review of previous methods is included in this report.

\section{INTRODUCTION}

An accurate calculation of the growth of turbulent boundary layers in a pressure gradient is required for many problems in hydrodynamics, aerodynamics and hydraulics where high Reynolds numbers are involved. Some of these problems are the calculation of the drag of airfoils and of bodies of revolution, the prediction of separation of flow on alrfoils, the prediction of flow conditions in the test sections and diffusers of water tunnels and wind tunnels, and the prediction of the flow (frictional wake) around the tails of bodies of revolution for use in designing propeliers and control surfaces.

Unlike laminar boundary layers, turbulent boundary layers are not very amenable to mathematical analysis owing to the present incomplete state of knowledge of the mechanics of turbulent flow. Nevertheless, considerable success in analyzing turbulent boundary layers on flat plates with zero pres- 
sure gradient has been achieved by such investigators as Prandtl and von Kármán. No comparable progress has been attained to date, however, in the theory of turbulent boundary layers in a pressure gradient, especially in an adverse (positive) pressure gradient.

Briefly, the current objective for analyzing turbulent boundary layers in a pressure gradient is to develop an equation for the variation of the shape of the velocity profile within the boundary layer. This formulation is required as an auxiliary equation for complementing the well-known von Kármán momentum equation. Auxiliary equations have been obtained empirically by a number of investigators. Because of significant differences existing among these empirical formulations, Tetervin and Lin attempted a theoretical approach to the problem. One of the equations obtained by them is a moment-of-momentum equation derived from the basic Prandtl boundary-layer equations and from a one-parameter characterization for the shape of the velocity profiles. Although the moment-of-momentum equation of Tetervin and Lin has the required form for an auxiliary equation, it lacks essential relations needed for numerical computations-namely, the variation with pressure gradient of the shearing stress at the surface (local skin friction) and of the integral of the distribution of the shearing stresses across the boundary layer. The principal aim of this paper is to supply the necessary shearingstress relations to this moment-of-momentum equation in order to develop a suitable auxiliary equation with a theoretical basis, to be used in conjunction with the von Kármán momentum equation.

The relation for the local skin friction in a pressure gradient is derived on the basis of the recent work of Ludwieg and Tillmann who demonstrated the validity of applying the so-called "law of the wall" to the inner flow in the boundary layer. The integral of the transverse distribution of the shearing stresses in a pressure gradient is found empirically in this paper to be a function of similar flat-plate data for zero pressure gradient.

The moment-of-momentum equation, after being modified by the inclusion of the shearing-stress relations, is demonstrated to agree with the average of other existing auxillary equations whose formulation is based on purely empirical grounds.

\section{FUNDAMENTAL RELATIONS FOR TURBULENT BOUNDARY LAYERS}

Some of the fundamentals of turbulent boundary layers are briefly reviewed here as an introduction to the subject. The comprehensive summarles by Prandtl, Goldstein, and Schlichting, References 1,2, and 3 respectively, should be referred to for fuller details.*

*References are listed on page 38. 
In general, steady fluid flow (quasi-steady for turbulent flow) manifests itself in two distinct types of motion, laminar at low Reynolds numbers and turbulent at high Reynolds numbers. Whereas laminar flow proceeds in a regular pattern of streamlines, turbulent flow advances in a haphazard combination of mixing motions. Although the variations in velocity and pressure of turbulent flow follow a random course, they may be considered to fluctuate about some mean value as shown in Figure 1.

The analytic treatment of turbulent flow consists in separating the fluid motion into a mean flow and a superposed fluctuation flow. Then the mean and fluctuation velocities and pressures are substituted into the Navier-Stokes equations for viscous flow and into the equation of continuity. After appropriate time averages are formed, the resulting equations in terms of mean quantities resemble those for laminar flow, with the exception of additional terms involving averages of various products of the fluctuation quantities. These fluctuation terms represent the mixing motion of turbulence and act as apparent stresses (Reynolds stresses) within the fluid. Since an analytical description of the Reynolds stresses has not been formulated, a direct solution of the differential equations for

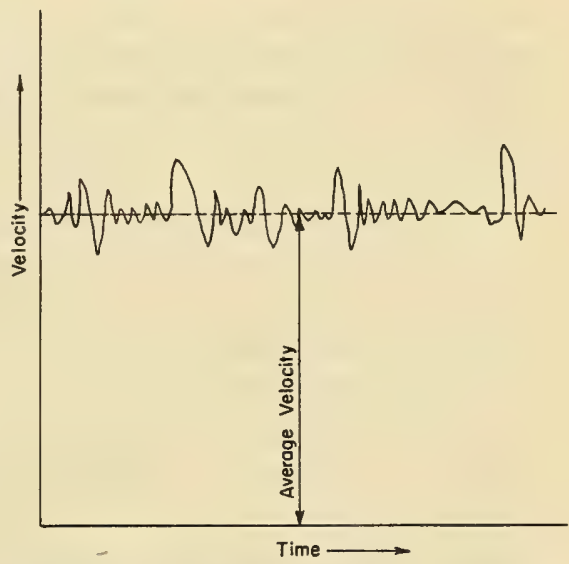

Figure 1 - Velocity Fluctuations of Turbulent Flow at a Fixed Position turbulent flow is virtually impossible.

The theory of the flow of viscous fluids serves as a useful guide, however, even though empirical or semi-empirical methods may be followed in many practical cases.

At relatively high Reynolds numbers, the viscous effects of fluids like air or water are confined mostly to a narrow region or band next to the solid surface. The laminar flow through this region, or boundary layer as it is better known, acts in the same manner as fully developed viscous flow in pipes, inasmuch as it becomes turbulent after a critical value of some Reynolds number is exceeded. The equations of motion for the turbulent boundary layer are found analytically from the Navier-Stokes equations for turbulent flow in a way analogous to that for the laminar boundary layer-that is, by 
rejecting terms involving small orders of magnitude. For steady incompressible flow with negligible longitudinal curvature, the turbulent-boundary-layer equations of motion are found to be

$$
u \frac{\partial u}{\partial x}+v \frac{\partial u}{\partial y}=-\frac{1}{\rho} \frac{\partial p}{\partial x}+\frac{1}{\rho} \frac{\partial \tau}{\partial y} ; \frac{\partial p}{\partial y}=0
$$

for $0 \leq y \leq \delta$ and $0 \leq u \leq U$. Here $u$ and $v$ are the $x$ - and $y$-components of the velocity within the boundary layer, parallel and normal to the surface of the body respectively, $U$ is the velocity at the outer edge of the boundary layer, $\delta$ is the thickness of the boundary layer, $\rho$ is the density of the fluid, and $\tau$ is the total shearing stress within the fluid. It is to be noted that the velocities and pressures indicated in Equation [1] represent time averages of the turbulent quantities in the flow. In addition to two-dimensional flow, Equation [1] is also applicable to axisymmetric flow when the boundary-layer thickness $\delta$ is small relative to the transverse radius of the solid boundary $r_{W}$.

The accompanying equation of continuity for two-dimensional flow is

$$
\frac{\partial u}{\partial x}+\frac{\partial v}{\partial y}=0
$$

and for axisymmetric flow it is

$$
\frac{\partial u}{\partial x}+\frac{\partial v}{\partial y}+\frac{u}{r_{w}} \frac{\partial r_{w}}{\partial x}=0
$$

for $\delta \ll r_{W}$.

From the boundary-layer equation of motion, Equation [1], and the equation of continuity, Equation [2], the von Kármán momentum equation is derived by integrating each term of [1] with respect to the y-coordinate. The von Kármán equation represents the basic working equation for calculating the growth of boundary layers in the presence of pressure gradients. For purposes of analysis the momentum equation is best expressed in terms of the displacement thickness $\delta^{*}$, the momentum thickness $\theta$ and the shape parameter $H$ which are defined as

$$
\begin{aligned}
& \delta^{*}=\int_{0}^{\delta}\left(1-\frac{\mathrm{u}}{\mathrm{U}}\right) \mathrm{dy} . \\
& \theta=\int_{0}^{\delta} \frac{\mathrm{u}}{\mathrm{U}}\left(1-\frac{\mathrm{u}}{\mathrm{U}}\right) \mathrm{dy}
\end{aligned}
$$

and

$$
H=\frac{\delta^{*}}{\theta}
$$


In terms of these quantities the von Kármán momentum equation for twodimensional f'low becomes

$$
\frac{d \theta}{d x}+(H+2) \frac{\theta}{U} \frac{d U}{d x}=\frac{\tau_{W}}{\rho U^{2}}
$$

and for axisymmetric flow it becomes for $\delta \ll r_{W}$

$$
\frac{d\left(r_{w} \theta\right)}{d x}+(H+2) \frac{r_{w} \theta}{U} \cdot \frac{d U}{d x}=r_{w} \frac{\tau_{w}}{\rho U^{2}}
$$

where $\tau_{W}$ is the shearing stress at the wall.

Physically the von Kármán momentum equation is interpreted as representing the rate of change of the momentum of the fluid within the boundary layer as a function of the frictional resistance and of the pressure gradient. When solving a particular problem, $U$, the velocity at the outer edge of the boundary layer, and $\mathrm{dU} / \mathrm{dx}$, representing the pressure gradient, are given by measurements from pressure taps on the body or by potential-flow calculations. Quantities such as the shape parameter $H$ and the local-skin-friction coefficient $\tau_{\mathrm{w}} / \rho \mathrm{U}^{2}$, have to be determined by other means. By assuming flat-plate values for $\mathrm{H}$ and $\tau_{\mathrm{W}} / \rho \mathrm{U}^{2}$, the momentum equation can be integrated to give an approximate solution which in many cases is not adequate for the problem in question. The more exact solution depends on acquiring auxiliary relations for the variation of $H$ and $\tau_{W} / \rho U^{2}$ in a pressure gradient. The detailed consideration of $\mathrm{H}$ and $\tau_{\mathrm{W}} / \rho \mathrm{U}^{2}$ in a pressure gradient is the major theme of this paper and will be discussed fully in the subsequent sections.

As an illustration of the flow idealized by boundary-layer theory, Figure 2 shows the flow pattern around a body of revolution. Essentially, there is potential flow outside the boundary layer and viscous flow within. The viscous boundary-layer flow is laminar from the nose up to the transition zone where it develops into a turbulent flow. Beyond the tail, the flow through the boundary layer merges to form a wake trailing behind the body.

The velocity. $U$ at the outer edge of the boundary layer is that of potential streamline and varies from zero at the stagnation point at the nose, through a range of values along the body to the free-stream velocity $U_{\infty}$ in the wake at infinity. Although the pressure $p$ at the outer edge of the boundary layer is essentially the same as that across the boundary layer, it varies along the body with $x$ and thus produces a pressure gradient. The pressure $p$ and the velocity $U$ of the potential streamline are related by the Bernoulli equation as follows 


$$
\mathrm{p}+\frac{1}{2} \rho \mathrm{U}^{2}=\text { constant }
$$

or

A negative pressure gradient is favorable and a positive pressure gradient adverse for preventing separation of flow.

Within the boundary layer the velocity $u$ is zero at the surface, since no slippage occurs, and increases to $U$ at the outer edge of the boundary layer. This variation of $u$ with $y$, or the velocity profile, is very important in the study of boundary layers. In the case of turbulent boundary layers, the following power law variation gives an excellent approximation for most flow conditions, and a rough approximation for strong adverse pressure gradients.

$$
\frac{\mathrm{u}}{\mathrm{U}}=\left(\frac{\mathrm{y}}{\delta}\right)^{n}
$$

where the value of the exponent $\mathrm{n}$ depends on the previous development of flow in the boundary layer.

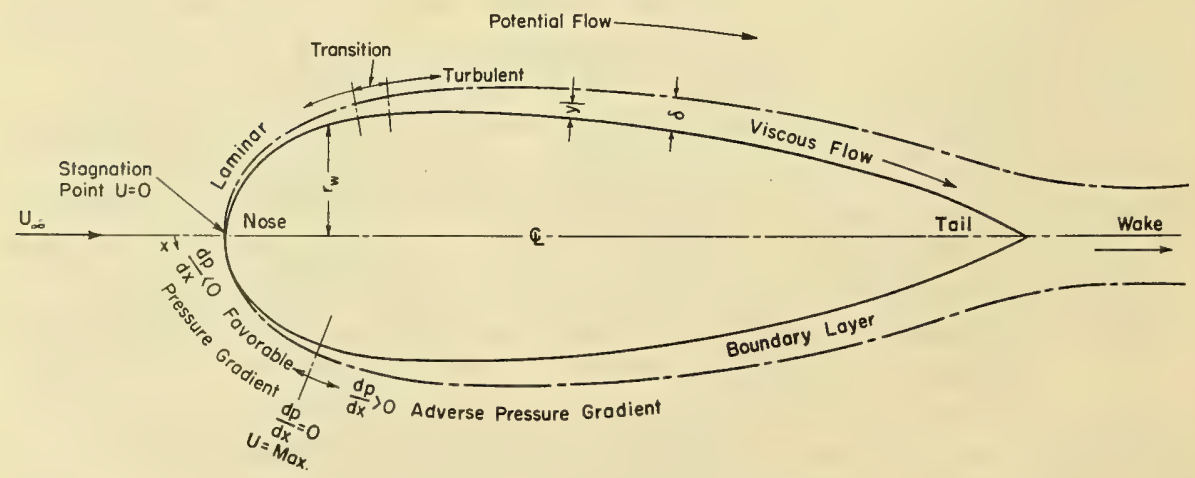

Figure 2 - Typical Boundary Layer Around a Body of Revolution 


\section{EXISTING METHODS FOR CALCULATING TURBULENT BOUNDARY LAYERS \\ IN A PRESSURE GRADIENT}

Interest in effects of pressure gradient on turbulent boundary layers has centered largely on adverse (positive) pressure gradients causing separation of flow such as occur in diverging conduits and on the suction side of airfoils at large angles of attack. (A review of the literature on this subject appears in Reference 4.) Since separation of flow is characterized by a reversal in the direction of flow at the surface, the velocity profile of the boundary layer suffers marked changes in shape as the flow approaches the point of separation, as seen in Figure 3. Hence the study of flow leading to separation must be directed towards the determination of the manner in which the shape of the velocity profile is affected by pressure gradients, as well as by other factors, such as Reynolds number.

Since a single parameter for the shape of the velocity profile greatly simplifies the mathematical analysis, considerable effort towards this goal has been expended by various investigators. Gruschwitz $z^{5}$ plotted $u / U$ against $\mathrm{y} / \theta$ in his experimental study of velocity profiles and, as shown in Figure 3, obtained a family of velocity profiles in various pressure gradients. He concluded that the value of $u / U$ at some standard value of $\mathrm{y} / \theta$ could be used to characterize the shape of the velocity profile for any pressure gradient. Following this concept Gruschwitz defined a form parameter $\eta$ such that

$$
\eta=1-\left(\frac{u}{U}\right)_{y=\theta}^{2}=1-\gamma^{2}
$$

where $\gamma=\left(\frac{u}{U}\right)_{y=\theta^{\circ}}$. Since the shape parameter $H$, which can be written

$$
H=\int_{0}^{\delta / \theta}\left(1-\frac{u}{U}\right) d\left(\frac{y}{\theta}\right)
$$

is also a function of the shape of the velocity profile, it cannot be independent of $\eta$ if the single-parameter relationship holds.

This is confirmed by Gruschwitz who plotted $H$ against $\eta$ for a series of test data. As seen in Figure 4, a falrly smooth variation between $\eta$ and $H$ results. It is to be noted that Kehl, ${ }^{6}$ from tests covering a wider range of Reynolds numbers than Gruschwitz, found that $\eta$ is not a unique function of $\mathrm{H}$ but that it varies slightly with Reynolds number. 


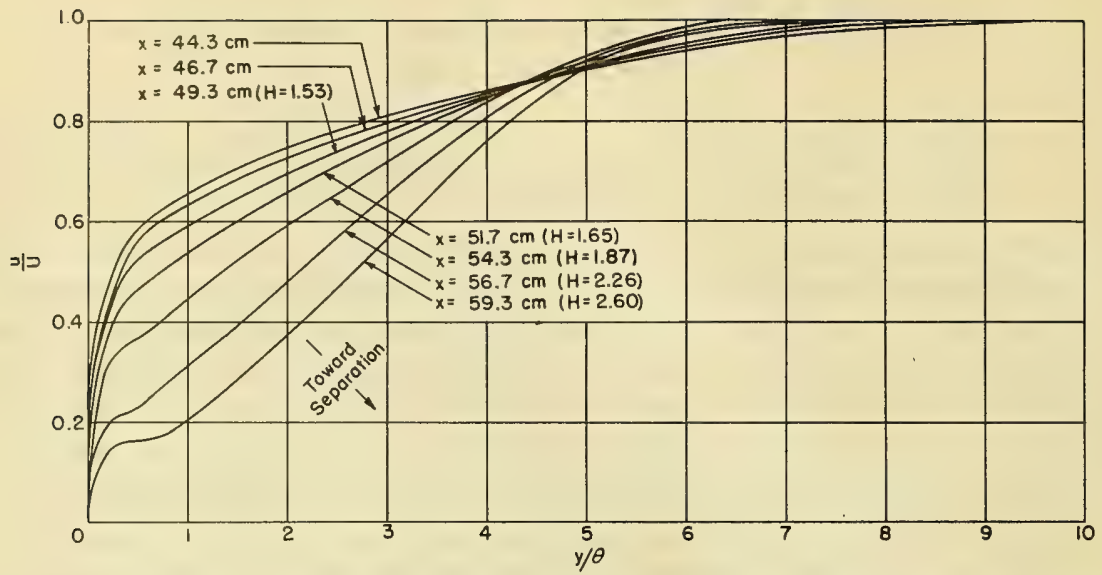

Figure 3 - Velocity Profiles of a Turbulent Boundary Layer In a Pressure Gradient (Gruschwitz, Reference 5)

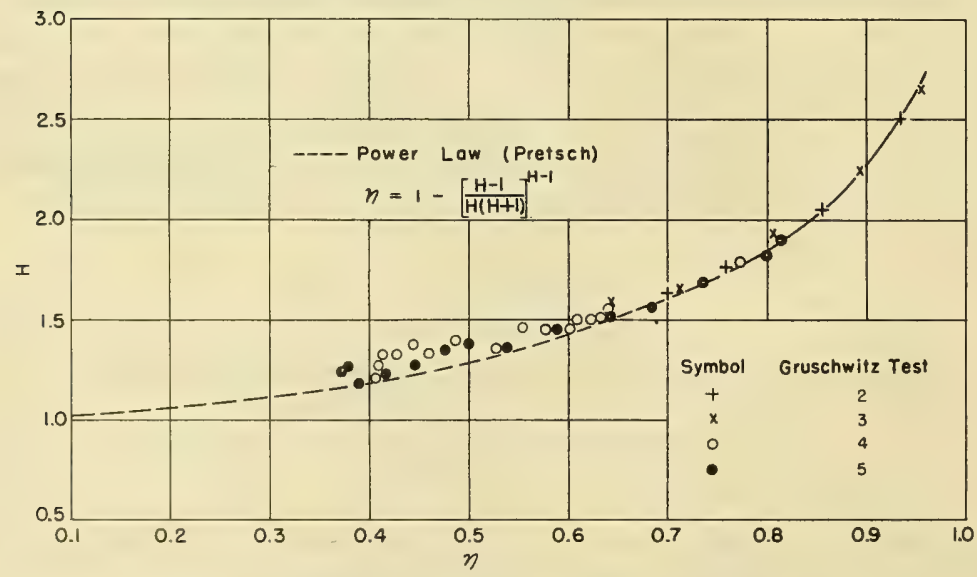

Figure 4 - Shape Parameter $H$ as Function of Gruschwitz Form Parameter $\eta$ (Schlichting, Reference 3)

Instead of $\eta$, von Doenhoff and Tetervin ${ }^{7}$ preferred the use of the shape parameter $\mathrm{H}$ itself as the single parameter to characterize the shape of the velocity profiles. Points from an extensive collection of test data were plotted together in the form

$$
\frac{u}{U}=f\left(\frac{y}{\theta}, H\right)
$$


As seen in Figure 5 , plots of $u / U$ against $H$ yield single curves for each value of $\mathrm{y} / \theta$.

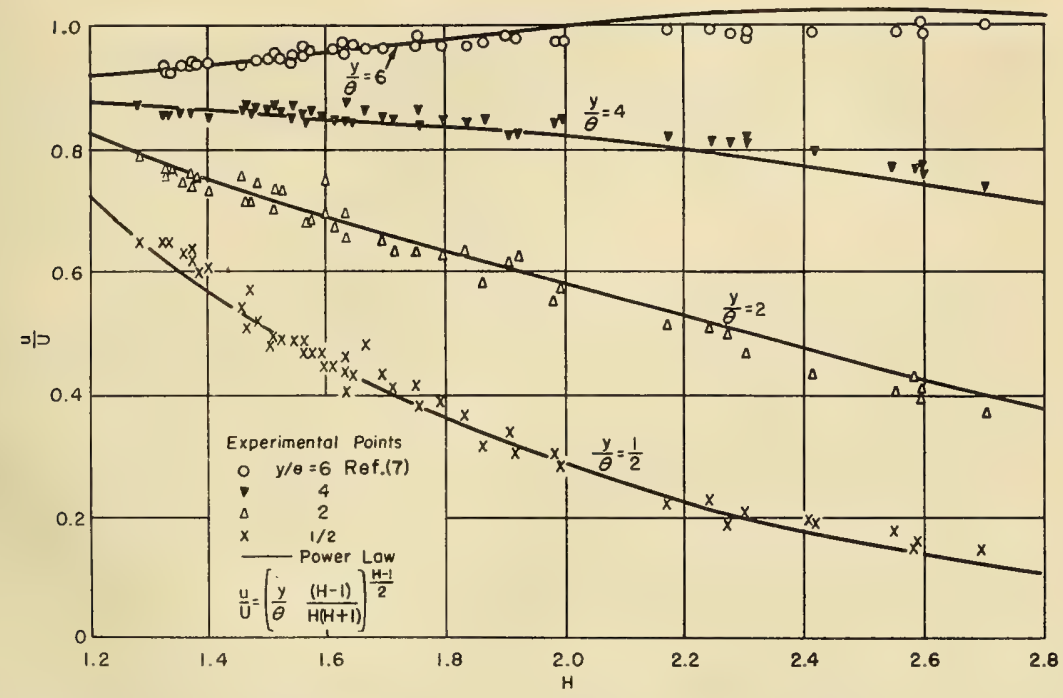

Figure 5 - Comparison of Power-Law Velocity Profiles with Experimental Points of von Doenhoff and Tetervin, Ref erence 7

For purposes of mathematical analysis it is found very useful to consider a general-power-law distribution for the velocity profiles of the form

$$
\frac{\mathrm{u}}{\mathrm{U}}=\left(\frac{\mathrm{y}}{\delta}\right)^{n}
$$

Using this power law Pretsch ${ }^{8}$ derived the following relations between the boundary-layer parameters

$$
\begin{gathered}
\frac{\delta^{*}}{\delta}=\frac{n}{n+1}=\frac{H-7}{H+1} \\
\frac{\theta}{\delta}=\frac{n}{(n+1)(2 n+7)}=\frac{H-1}{H(H+1)} \\
H=2 n+1
\end{gathered}
$$


and finally

$$
\eta=1-\left[\frac{H-1}{H(H+1)}\right]^{H-1}
$$

The curve for the relation just derived for $\eta(H)$ is drawn on Figure 4 and shows close agreement with the test data of Gruschwitz. Likewise the curve for the power law for the velocity profiles may be expressed in the form

$$
\frac{\mathrm{u}}{\mathrm{U}}=\left[\left(\frac{\mathrm{y}}{\theta}\right) \frac{\mathrm{H}-1}{\mathrm{H}(\mathrm{H}+1)}\right]^{\frac{H-1}{2}}
$$

Curves drawn from this equation in Figure 5 show close agreement with the data of von Doenhoff and Tetervin. From the experimental evidence just considered, it is seen that the general power law is an excellent approximation for the velocity profiles of turbulent boundary layers.

After the particular parameter for the shape of the velocity profile has been selected, its varlation in a pressure gradient remains to be determined. It is now recognized that the rate of variation of this shape parameter and not the parameter itself is dependent upon the local-pressuregradient parameter and upon other local parameters of the boundary layer. However, an early study by Buri ${ }^{9}$ in 1931 on accelerated and retarded flows in closed conduits considered the shape of the velocity profile to depend directly on the pressure gradient.

The parameter used by Burl for the shape of the velocity profile is

$$
\Gamma=\frac{\theta}{\mathrm{U}} \frac{\mathrm{dU}}{\mathrm{dx}} \mathrm{R}_{\theta}^{1 / 4}
$$

where $\mathrm{R}_{\theta}=\frac{\mathrm{U} \theta}{\nu}$ and $\nu$ is the kinematic viscosity of the fluid. Actually $\Gamma$ is a local parameter for the pressure gradient and hence can only roughly represent the shape of the velocity profile whose development depends on the previous history of the flow. The parameter $\Gamma$ as used by Buri in his analysis has merit in providing a simplified method for calculating the momentum thickness $\theta$ approximately. When $\Gamma$ is substituted into the von Kármán momentum equation, Equation [6a], the following expression is obtalned

$$
\frac{\mathrm{d}}{\mathrm{dx}}\left(\mathrm{R}_{\theta}^{1 / 4} \theta\right)=\frac{5}{4}\left[\zeta-\Gamma\left(\mathrm{H}+\frac{9}{5}\right)\right]
$$

where $\zeta=\frac{{ }^{T} \mathrm{~W}}{\rho \mathrm{U}^{2}} \mathrm{R}_{\theta}^{1 / 4}$. From experimental evidence, Burl linearized this exexpression to

$$
\frac{\mathrm{d}}{\mathrm{dx}}\left(\mathrm{R}_{\theta}^{1 / 4} \theta\right)=\mathrm{a}-\mathrm{b} \Gamma
$$


or

$$
\frac{d}{d x}\left(R_{\theta}^{1 / 4} \theta\right)=a-\frac{b}{U} \frac{d U}{d x}\left(R_{\theta}^{1 / 4} \theta\right)
$$

where $a$ and $b$ are empirical constants. Equation [19] is integrated as a linear first-order equation in terms of $\mathrm{R}_{\theta}^{1 / 4} \theta$ to provide a direct solution for the momentum thickness $\theta$. From test data Buri considered separation to occur at $\Gamma=-0.06$. The Buri method of analysis was continued by Howarth ${ }^{10}$ who refined the method by solving Equation [18] directly, using experimental data for $\zeta$ and $H$.

At the same time that Buri published his work, Gruschwitz ${ }^{5}$ presented a more satisfactory method of analysis. Introducing the shape parameter $\eta$ and realizing that 1 ts rate of change in a pressure gradient is more important than its local value, Gruschwitz plotted the nondimensional differential quantity $-\frac{\theta}{U^{2}} \frac{d}{d x}\left(U^{2} \eta\right)$ against $\eta$ and obtained a linear variation for his test data as shown in Figure 6. Although Gruschwitz expected some effect due to Reynolds number, the narrow range of his data, $1 \times 10^{3}<R_{\theta}<4 \times 10^{3}$, precluded any such indication and consequently he included no Reynolds number

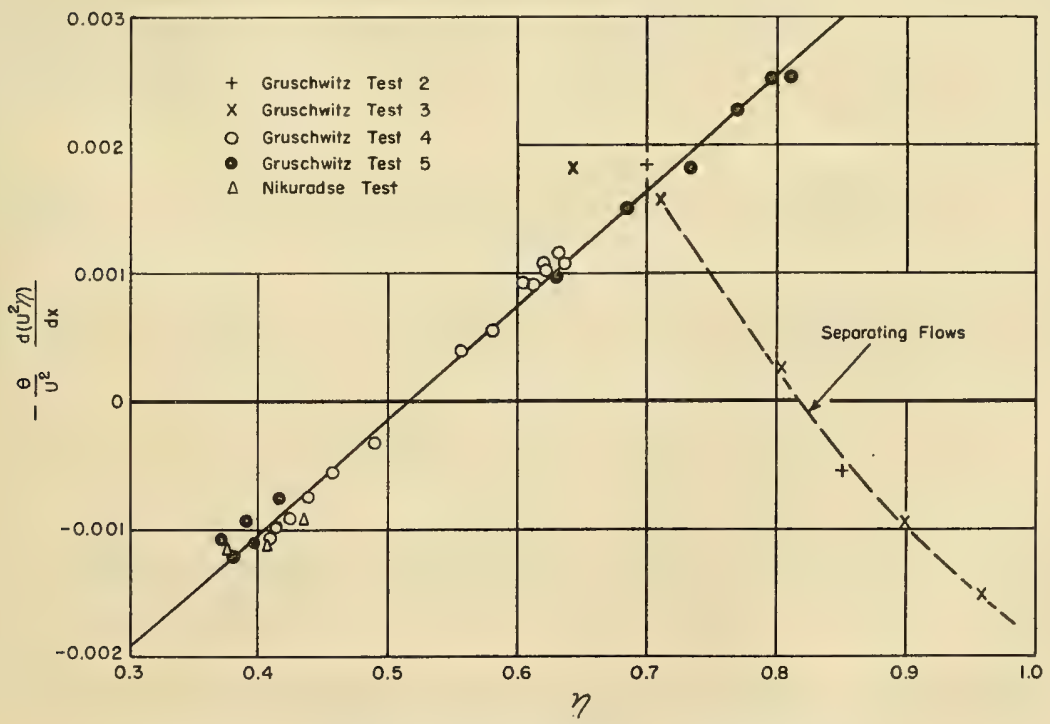

Figure 6 - Gruschwitz Form Parameter $\eta$ as Function of Pressure Gradient (Gruschwitz, Reference 5) 
effect in his analysis. The empirical equation fitting his test points is given as

$$
-\frac{\theta}{U^{2}} \frac{d\left(U^{2} \eta\right)}{d x}=0.00894 \eta-0.00461
$$

for $\eta<0.8$. When $\frac{\theta}{U^{2}} \frac{d\left(U^{2} \eta\right)}{d x}$ is expanded to $\theta \frac{d \eta}{d x}+2 \eta\left(\frac{\theta}{U} \frac{d U}{d x}\right)$, It is seen that the rate of variation of $\eta, \mathrm{d} \eta / \mathrm{dx}$, and the nondimensional pressure gradient $\frac{\theta}{U} \frac{d U}{d x}$ are both included in Equation [20]. The variation of $\eta$ is calculated from the auxiliary equation, [20], when used simultaneously with the von Kármán momentum equation. Gruschwitz considered separation to occur at $\eta \geqslant 0.8$ which is equivalent to $H \geqslant 1.85$.

From test data covering a wider range of Reynolds numbers, $1 \times 10^{3}<R_{\theta}<3.5 \times 10^{4}, \mathrm{Kehl}^{6}$ incorporated the effect of Reynolds number in the Gruschwitz equation and obtained

$$
-\frac{\theta}{U^{2}} \frac{d\left(U^{2} \eta\right)}{d x}=0.00894 \eta-\frac{0.0164}{\log _{10} R_{\theta}}+\frac{0.85}{\left(R_{\theta}-300\right)}
$$

Using $H$ rather than $\eta$ as the single parameter for the shape of the velocity profiles, von Doenhoff and Tetervin ${ }^{7}$ made an empirical study of the variation of $H$ in pressure gradients in order to obtain an auxiliary equation. From a collection of NACA and other test data representing a range of Reynolds numbers, $1 \times 10^{3}<R_{\theta}<7 \times 10^{4}$ roughly, they considered the rate of change of $\mathrm{H}$ to vary as follows

$$
\theta \frac{\mathrm{dH}}{\mathrm{dx}}=\left[-2.035(\mathrm{H}-1.286)-\frac{2}{\frac{\tau_{\mathrm{W}_{0}}}{\rho \mathrm{U}^{2}}}\left(\frac{\theta}{\mathrm{U}} \frac{\mathrm{dU}}{\mathrm{dx}}\right)\right] \mathrm{e}^{4.680(\mathrm{H}-2.975)}
$$

where $\tau_{W_{0}} / \rho U^{2}$ is taken from the flat plate formula of Squire and Young ${ }^{11}$

$$
\frac{\tau_{W_{0}}}{\rho U^{2}}=\left[\frac{1}{5.890 \log _{10}\left(4.075 R_{\theta}\right)}\right]^{2}
$$

Von Doenhoff and Tetervin considered separation to occur in the range $1.8<\mathrm{H}<2.6$. It is to be noted that the pressure-gradient parameter is $\frac{\theta}{U} \frac{\mathrm{dU}}{\mathrm{dx}}$ and the parameter representing the Reynolds-number effect is $\tau_{\mathrm{w}_{0}} / \rho U^{2}$, the local-skin-friction coefficient. Although these parameters are satisfactory in themselves for describing the flow, their combination into a single term in the empirical equation seems objectionable for analysis. 
Using substantially the same data as von Doenhoff and Tetervin and a somewhat different analysis, Garner ${ }^{12}$ obtained a more amenable auxiliary equation for the rate of variation of $\mathrm{H}$

$$
\theta \frac{\mathrm{dH}}{\mathrm{dx}}=\left[-\frac{0.0135(\mathrm{H}-1.4)}{\mathrm{R}_{\theta}^{1 / 6}}-\frac{\theta}{\mathrm{U}} \frac{\mathrm{dU}}{\mathrm{dx}}\right] e^{5(\mathrm{H}-1.4)}
$$

The following flat-plate formula of Falkner's for the skin-frictioncoefficient is used in 1ts determination

$$
\frac{\tau_{W_{0}}}{\rho U^{2}}=\frac{0.006534}{R_{\theta}^{1 / 6}}
$$

A noteworthy feature of Garner's equation is the separation of the pressuregradient parameter $\frac{\theta}{U} \frac{d U}{d x}$ and the Reynolds number $R_{\theta}$ into different terms.

Theoretical derivations of an auxiliary equation have proved very difficult. A strenuous but unsuccessful effort was made by Coleman ${ }^{14}$ in 1947. A very promising avenue of approach was introduced, however, more recently by Tetervin and $\mathrm{Lin}^{15}$ who investigated various integral forms of the Prandtl boundary-layer equation, [1]. By multiplying each term of this equation by an arbitrary function and then integrating, it is possible to derive various families of equations. Using as the multiplying function $\mathrm{u}^{\mathrm{s}_{1}} \mathrm{y}^{\mathrm{s}_{2}}$, where $\mathrm{s}_{1}$ and $s_{2}$ are arbitrary constants, the general integral form of the boundarylayer equation is written

$$
\int_{0}^{\delta} u \frac{\partial u}{\partial x} u^{s_{1}} y^{s_{2}} d y+\int_{0}^{\delta} v \frac{\partial u}{\partial y} u^{s_{1}} y^{s_{2}} d y=-\frac{1}{\rho} \int_{0}^{\delta} \frac{d p}{d x} u^{s_{1}} y^{s_{2}} d y+\frac{1}{\rho} \int_{0}^{\delta} \frac{\partial \tau}{\partial y} u^{s_{1}} y^{s_{2}} d y
$$

As before, this equation is accompanied by the equation of continuity, [2]. When both exponents $s_{1}$ and $s_{2}$ are set equal to zero, the von Kármán momentum equation is specified. When $s_{1}=1$ and $s_{2}=0$, an energy equation results; when $s_{1}=0$ and $s_{2}=1$, a moment-of-momentum equation is indicated.

The moment-of-momentum equation appears to be the most promising of these derived integrated equations for obtaining a theoretical auxiliary equation for the variation of $\mathrm{H}$. Assuming the general-power-law distribution for the velocity profile, [8], Tetervin and Lin obtained the moment-of-momentum equation in the form

$$
\theta \frac{d H}{d x}=-\frac{H(H+1)\left(H^{2}-1\right)}{2} \frac{\theta}{U} \frac{d U}{d x}+H\left(H^{2}-1\right) \frac{\tau_{W}}{\rho U^{2}}-(H+1)\left(H^{2}-1\right) \int_{0}^{1} \frac{\tau}{\rho U^{2}} d\left(\frac{y}{\delta}\right)
$$


This equation is applicable to two-dimensional flows and to axisymmetric flows $\left(\delta<<r_{W}\right)$. For purposes of calculation it is seen that relations for the variation of the shearing stresses in a pressure gradient are still required. The main objective of this paper is the conversion of the above equation into a usable auxiliary equation by supplying relations for the variation in a pressure gradient of the local-skin-friction coefficient $\tau_{W} / \rho U^{2}$ and the integral of the shearing-stress distribution $\int_{0}^{1} \frac{\tau}{\rho U^{2}} d\left(\frac{y}{\delta}\right)$.

For comparison the various auxiliary equations for the variation of the shape parameter in a pressure gradient are listed in Table 1 . It is seen that Buri's method does not provide for an auxiliary equation since no allowance is made for the effect of the previous development of the flow. On the other hand, the Gruschwitz method is correct in utilizing the rate of change of a shape parameter in its analytic formulation. It is seen that Kehl removed one of the main objections to the Gruschwitz method by incorporating the

\section{TABLE 1}

Summary of Methods for Calculating the Turbulent Boundary Layer in a Pressure Gradient

\begin{tabular}{|c|c|c|c|}
\hline Investigator & $\begin{array}{l}\text { Criterion } \\
\text { for } \\
\text { Separation }\end{array}$ & $\begin{array}{l}\text { Auxiliary Equation } \\
\text { (for use with von Kármán Momentum Equation) }\end{array}$ & Remarks \\
\hline $\begin{array}{l}\text { Bur1, } 1931 \\
\text { Reference } 9\end{array}$ & $F=-0.06$ & $\begin{array}{l}\text { None explicitly; von Kármán momentum equation modified to } \\
\qquad \frac{\mathrm{d}}{\mathrm{dx}}\left(\mathrm{R}_{\theta}^{\frac{1}{4}} \theta\right)=\mathrm{a}-\mathrm{b} \Gamma\end{array}$ & $\begin{array}{l}\Gamma \text { is not proper param- } \\
\text { eter for shape of ve- } \\
\text { locity proflle; no } \\
\text { allowance in method } \\
\text { for effect of previous } \\
\text { development of flow in } \\
\text { boundary layer }\end{array}$ \\
\hline $\begin{array}{l}\text { Gruschwitz, } \\
1931 \\
\text { Reference } 5\end{array}$ & $\eta \geqslant 0.8$ & $-\frac{\theta}{U^{2}} \frac{d\left(U^{2} \eta\right)}{d x}=0.00894 \eta-0.00461$ & $\begin{array}{l}\text { No Reynolds-number ef- } \\
\text { fect Included; based } \\
\text { on test data; } \\
1 \times 10^{3}<\mathrm{R}_{8}<4 \times 10^{3}\end{array}$ \\
\hline $\begin{array}{l}\text { Kehl, } 1943 \\
\text { Reference } 6\end{array}$ & & $-\frac{\theta}{U^{2}} \frac{d\left(U^{2} \eta\right)}{d x}=0.00894 \eta-\frac{0.0164}{\log _{10} R_{\theta}}+\frac{0.85}{\left(R_{0}-300\right)}$ & $\begin{array}{l}\text { Gruschwitz method ex- } \\
\text { tended to include ef- } \\
\text { fects of Reynolds num- } \\
\text { ber; based on test data } \\
1 \times 10^{3}<\mathrm{R}, \leq 3.5 \times 10^{4} \\
\end{array}$ \\
\hline $\begin{array}{l}\text { von Doenhoff } \\
\text { and Tetervin, } \\
1943 \text {, } \\
\text { Reference } 7\end{array}$ & $1.8<\mathrm{H}<2.6$ & 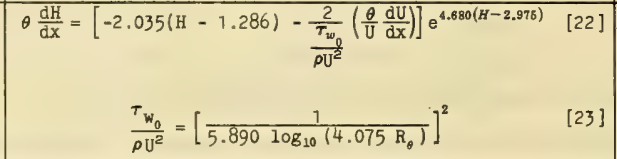 & $\begin{array}{l}\text { Emplrical; based on } \\
\text { test data, } \\
1 \times 10^{3}<R_{\theta}<7 \times 10^{4}\end{array}$ \\
\hline $\begin{array}{l}\text { Garner, } 1944 \\
\text { Reference } 12\end{array}$ & $H=2.6$ & $\theta \frac{\mathrm{dH}}{\mathrm{dx}}=\left[-\frac{0.0135(\mathrm{H}-1.4)}{\mathrm{R}_{\theta}^{1 / 8}}-\frac{\theta}{U} \frac{\mathrm{dU}}{\mathrm{dx}}\right] \mathrm{e}^{5(H-1.4)}$ & $\begin{array}{l}\text { Based mostly on same } \\
\text { data as von Doenhoff } \\
\text { and Tetervin } \\
\end{array}$ \\
\hline $\begin{array}{l}\text { Tetervin and } \\
\text { Lin, } 1950 \text {, } \\
\text { Reference } 15\end{array}$ & & $\begin{aligned} \theta \frac{\mathrm{dH}}{\mathrm{dx}} & =-\frac{H(H+1)\left(H^{2}-1\right)}{2} \frac{\theta}{U} \frac{\mathrm{dU}}{\mathrm{dx}} \\
& +H\left(H^{2}-1\right)^{\top} \frac{\mathrm{W}}{\rho U^{2}}-(H+1)\left(H^{2}-1\right) \int_{0}^{1} \frac{\tau}{\rho U^{2}} d\left(\frac{y}{\delta}\right)\end{aligned}$ & $\begin{array}{l}\text { Theoretically derived } \\
\text { but lacking in shear- } \\
\text { 1ng-stress information } \\
\text { required for numerical } \\
\text { solution }\end{array}$ \\
\hline
\end{tabular}


effects of Reynolds number. Mention is made of an experimental study of the Gruschwitz method by Peters ${ }^{16}$ who found that it gave fair results for $\eta$ but that it seemed useless for predicting separation. The form of the Garner equation is superior to that of the von Doenhoff and Tetervin equations because it separates the pressure-gradient parameter and the Reynolds-number effect. A critical comparison of the two equations just mentioned, made by Fage and Raymer, ${ }^{17}$ claimed serious numerical discrepancies between them even though they had both been derived for the most part from the same test data. The moment-of-momentum equation developed in the present report will be found similar in form to that of the Garner equation. A graphical comparison of all the methods w1th the exception of the Buri method is shown at the end of this report.

\section{LOCAL SKIN FRICTION AS A FUNCTION OF PRESSURE GRADIENT}

The manner of the variation of the local skin friction or shearing stress at the wall $\tau_{\text {w }}$ with pressure gradient as well as with Reynolds number is required in both the von Kármán momentum equation and the moment-of momentum equation. Until recently the experimental study of wall shearing stresses was hindered by the poor precision of the existing experimental techniques, based on measuring the rate of change of the momentum and the pressure of the flow through the boundary layer. In 1949 Ludwieg and Tillmann ${ }^{18}$ introduced a new method for accurately measuring the wall shearing stress in a pressure gradient. The improved technique, described in Reference 19, consists in measuring the rate of heat transferred to the fluid from a calibrated instrument imbedded in the wall. From their measurements Ludwieg and Tillmann proved that the wall shearing stress diminishes in an adverse pressure gradient, even close to the separation point. In addition, they demonstrated that the so-called "law of the wall" can be used for a quantitative analysis of the variation of the wall shearing stress in a pressure gradient.

The "law of the wall"20 states that within the boundary layer in a pressure gradient there is a region of flow next to the wall which has velocity and skin-friction characteristics similar to that of a flat plate in a zero pressure gradient. As seen in Figure 7 this region of flow or inner flow has subregions of a laminar sublayer and a transition zone. The Prandt friction-velocity relationship for a flat plate ${ }^{2}$ can then be applied to the whole inner flow or

$$
\frac{u}{u_{\tau}}=f\left(\frac{u_{\tau} y}{v}\right)
$$


where $u_{\tau}=\sqrt{\frac{T_{W}}{\rho}}$ is the friction velocity. The functional relationship satisfying the turbulent portion of the inner flow is

$$
\frac{u}{u_{\tau}}=c_{1}+c_{2} \log \left(\frac{u_{\tau} y}{v}\right)
$$

For simplicity of analysis, the above logarithmic formulation can be closely approximated by the general power law

$$
\frac{u}{u_{\tau}}=C\left(\frac{u_{\tau} y}{\nu}\right)^{n_{0}}
$$

By virtue of the law of the wall, $C$ and $n_{0}$ are independent of pressure gradient and depend only on the Reynolds number. The applicability of the powerlaw formulation is demonstrated in Figure 8 where a logarithmic plot of $u / U$ against $y / \theta$ is shown for varlous pressure gradients. It is seen that the curves are straight and parallel up to about $y=\theta$. This situation can be explained analytically from the power law as follows. Substituting $y=\theta$ and $u=u_{\theta}$ into the power law gives

$$
\frac{u_{\theta}}{u_{\tau}}=C\left(\frac{u_{\tau} \theta}{\nu}\right)^{n_{0}}
$$

Dividing Equation [30] by [31] produces

$$
\frac{\mathrm{u}}{\mathrm{u}_{\theta}}=\left(\frac{\mathrm{y}}{\theta}\right)^{n_{0}}
$$

or

$$
\log \frac{u}{U}=\log \frac{u_{\theta}}{U}+n_{0} \log \frac{y}{\theta}
$$

Since $n_{0}$ does not depend on pressure gradient, the curves of $l 0 g u / U$ should be straight and parallel up to $\mathrm{y}=\boldsymbol{\theta}$.

Ludwieg and Tillmann demonstrated experimentally that the law of the wall is also valld for analyzing the variation of the wall shearing stress in a pressure gradient. From test data in the range of Reynolds number $1 \times 10^{3} \leqslant R_{\theta} \leqslant 4 \times 10^{4}$, they obtained the following expression for the varlation of the local-skin-friction coefficient in a pressure gradient

$$
\frac{\tau_{W}}{\rho \mathrm{U}^{2}}=\frac{0.0290}{\mathrm{R}_{\theta}^{0.268}} \gamma 1.705
$$

where

$$
\gamma=2.333 \times 10^{-0.398 \mathrm{H}}
$$


A general equation for the variation of the skin friction in a pressure gradient will now be derlved from the law of the wall by using the powerlaw formula for the velocity profile of the inner flow,

$$
\frac{u}{u_{\tau}}=c\left(\frac{u_{\tau} y}{\nu}\right)^{n_{0}}
$$

As before, at $\mathrm{y}=\theta, \mathrm{u}=\mathrm{u}_{\theta}$ and

$$
\frac{u_{\theta}}{u_{\tau}}=c\left(\frac{u_{\tau} \theta}{\nu}\right)^{n_{0}}
$$

After substituting $u_{\tau}=\sqrt{\frac{T_{W}}{\rho}}$ and $\gamma=\frac{u_{\theta}}{U}$, there results

$$
\frac{\tau_{\mathrm{W}}}{\rho \mathrm{U}^{2}}=\left(\mathrm{CR}_{\theta}^{n_{0}}\right)^{-\frac{2}{1+n_{0}}} \quad \gamma^{\frac{2}{1+n_{0}}}
$$

For two different pressure gradients at the same Reynolds number $R_{\theta}$ and consequently at the same value of $C$ and $n_{0}$, the following ratio can be formed

$$
\frac{\left(\frac{\tau_{\mathrm{W}}}{\rho \mathrm{U}^{2}}\right)_{1}}{\left(\frac{{ }_{\mathrm{W}}}{\rho \mathrm{U}^{2}}\right)_{2}}=\left(\frac{\gamma_{1}}{\gamma_{2}}\right)^{\frac{2}{1+n_{0}}}
$$

If the reference condition is that for zero pressure gradient, this equation becomes

$$
\frac{\tau_{W}}{\rho U^{2}}=\left(\frac{\tau_{W_{0}}}{\rho U^{2}}\right)\left(\frac{\gamma}{\gamma_{0}}\right)^{\frac{2}{1+n_{0}}}
$$

where the subscript zero refers to zero pressure gradient. For a powerlaw velocity profile of a flat plate with zero pressure gradient, Equation [14] becomes

$$
\mathrm{n}_{0}=\frac{\mathrm{H}_{0}-1}{2}
$$

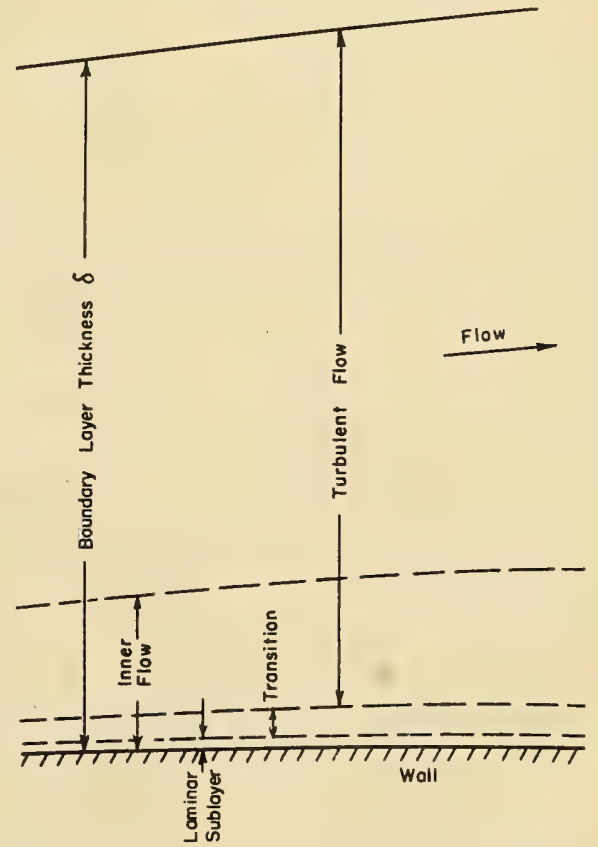

Figure 7 - Regions of Flow Within the Turbulent Boundary Layer in a Pressure Gradient 


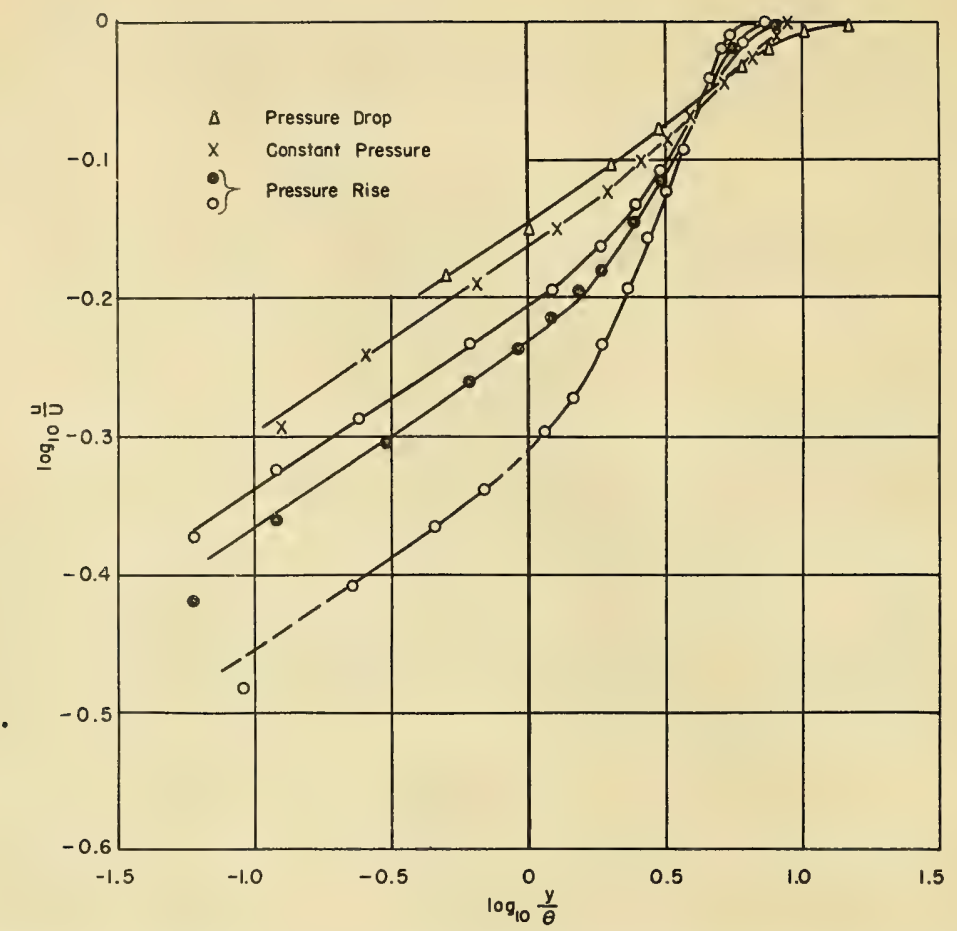

Figure 8 - Logarithmic Plot of Velocity Profiles in Pressure Gradients s Illustrating "The Law of the Wall" (Ludwleg and Tillmann, Reference 18)

Then [38] reduces to

$$
\frac{\tau_{W}}{\rho U^{2}}=\frac{\tau_{W_{0}}}{\rho U^{2}}\left(\frac{\gamma}{\gamma_{0}}\right)^{\frac{4}{H_{0}+1}}
$$

Comparing the exponents of $\gamma$ in [34] and [40], it is seen that the exponent obtained by Ludwieg and Tillmann has a constant value of 1.705 while that of the equation just derived depends on $H_{0}$, which varies with Reynolds number. From Figure 11 showing the variation of $H_{0}$ with $R_{\theta}$, the exponent $4 / H_{0}+1$ is found equal $t 0^{*} 1.639$ for $R_{\theta}=1.5 \times 10^{3}$, and 1.800 for $R_{\theta}=4 \times 10^{4}$. These values compare favorably with the value 1.705 of Ludwieg and Tilimann. 


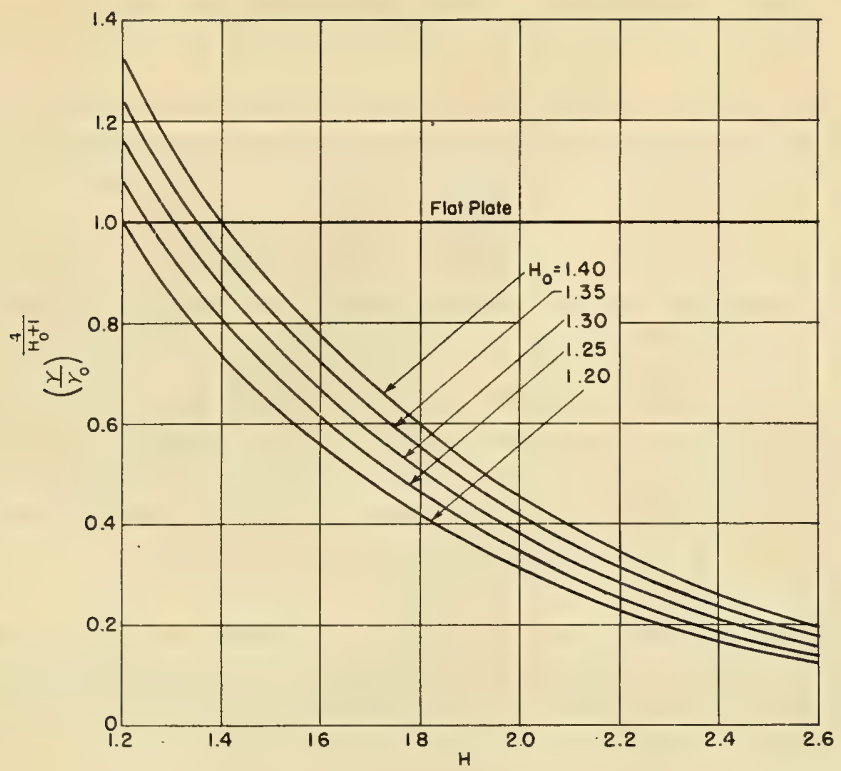

Figure 9 - The Variation of Pressure-Gradient Factor $\left(\frac{\gamma}{\gamma_{0}}\right)^{\frac{4}{H_{0}+1}}$ with
$H$ for Different Values of $\mathrm{H}_{0}$

Since from Equation [9]

$$
\gamma=\sqrt{1-\eta}
$$

$\gamma$ may be expressed as a function of $\mathrm{H}$ using [15],

$$
\gamma=\left[\frac{H-1}{H(H+1)}\right]^{\frac{H-1}{2}}
$$

and

$$
\gamma_{0}=\left[\frac{H_{0}-1}{H_{0}\left(H_{0}+1\right)}\right]^{\frac{H_{0}-1}{2}}
$$

The variation of $\left(\frac{\gamma}{\gamma_{0}}\right)^{\frac{4}{H_{0}+1}}$ with $H$ and $H_{0}$ is shown in Figure 9 . Since this factor which represents the effect of pressure gradient on the skin friction diminishes asymptotically towards zero, with increasing $H$, it can only describe flow conditions approaching separation and not conditions right at the separation point where the wall shearing stress is zero. 


\section{LOCAL-SKIN-FRICTION COEFFICIENTS FOR FLAT PLATES \\ AT ZERO PRESSURE GRADIENT}

Since the evaluation of the local skin friction in a pressure gradient depends on a knowledge of its value in zero pressure gradient, as seen in Equation [40], a review of avallable information on the drag of flat plates should now be considered. A smooth flat plate moving parallel to the direction of motion represents an excellent example of boundary-layer flow in a zero pressure gradient. The analytic study of the drag of flat plates has proceeded on a semi-empirical basis by such investigators as Prandtl and von Kármán. ${ }^{1,2}$ From various theoretical and empirical considerations a functional form is assumed for the velocity profile involving both the velocity and the local skin friction. Then an integration over the length of the plate leads to a general expression for the drag, containing coefficierits to be numerically evaluated from test data. Landweber ${ }^{21}$ has made a critical review of such methods.

For the boundary-layer relations considered in this report it is necessary to express the frictional resistance of flat plates in terms of a local-skin-friction coefficient as a function of a local Reynolds number or

$$
\frac{{ }^{\tau} \mathrm{W}_{0}}{\rho \mathrm{U}^{2}}=\mathrm{f}\left(\mathrm{R}_{\theta}\right)
$$

where $\mathrm{R}_{\theta}=\frac{\mathrm{U} \theta}{\nu}$. Various investigators have developed expressions of this type from drag coefficient formulas appearing in the literature.

Tetervin ${ }^{22}$ obtained the following local-skin-friction formula for flat plates from the universal resistance law for pipes

$$
\frac{\tau_{w_{0}}}{\rho U^{2}}=\left\{\frac{1}{2.5 \ln \left[\frac{R_{\theta}}{2.5\left(1-5 \sqrt{\frac{\tau}{\rho U_{0}^{2}}}\right]}\right]+5.5}\right\}^{2}
$$

Since $\tau_{w_{0}} / \rho U^{2}$ appears also on the right hand side, it is an unwieldly equation to use numerically. Furthermore, as it is based on pipe-resistance data, it applies only approximately to flat plates.

Squire and Young ${ }^{11}$, by a combination of the von Kármán asymptotic formula and the Prandtl and Schlichting drag law, derived the following expression for the local-skin-friction coefficient

$$
\frac{\tau_{W_{0}}}{\rho U^{2}}=\left[\frac{1}{5.890 \log _{10}\left(4.075 R_{\theta}\right)}\right]^{2}
$$


The Prandtl and Schlichting drag law has been critlcized for its use of pipe velocity profiles in its derivation. ${ }^{3}$

Falkner, ${ }^{13}$ by a study of various test data for flat plates, proposed the following simple power-law formula

$$
\frac{\tau_{W_{0}}}{\rho U^{2}}=\frac{0.006534}{R_{\theta}^{1 / 6}}
$$

Like all power-law formulas, this equation is valld only for a limited range of Reynolds numbers.

Ludwieg and Tillmann ${ }^{18}$ derlved the following equation from the test data of Schultz-Grunow ${ }^{23}$

$$
\frac{\tau_{W_{0}}}{\rho U^{2}}=\frac{0.0167}{\left(\log _{10} R_{\theta}\right)^{1.838}}
$$

for $2 \times 10^{3}<R_{\theta}<7 \times 10^{5}$.

A local-skin-friction formula will now be derived from the wellknown Schoenherr (Kármán-Schoenherr) frictional-resistance formula for flat plates. From an extensive collection of test data for the frictional resistance of flat plates covering a wide range of Reynolds numbers, Schoenherr ${ }^{24}$ supplied numerical values to the coefficlents of the von Kármán asymptotic drag-law formula. The Schoenherr formula has become the basis of frictionalresistance calculations for the prediction of full-scale horsepower from tests on models of ships. The Schoenherr formula is

$$
\frac{1}{C_{f}^{1 / 2}}=4.13 \log _{10}\left(R_{x} C_{f}\right)
$$

where $R_{x}=\frac{U x}{\nu}$. Here

$$
C_{f}=\frac{D}{\frac{1}{2} \rho U^{2} S}
$$

where $D$ is the drag and $S$ is the total surface area. Hence for a flat plate of width $W$ and length $x$ the drag of one side is

$$
D=C_{f} \frac{1}{2} \rho U^{2} x W
$$


For a flat plate with zero pressure gradient the von Kármán momentum equation reduces to

$$
\frac{\mathrm{d} \theta}{\mathrm{dx}}=\frac{\tau_{\mathrm{w}_{0}}}{\rho \mathrm{U}^{2}}
$$

or

$$
\theta=\frac{1}{\rho U^{2}} \int_{0}^{x} \tau_{w_{0}} d x
$$

or

$$
\theta=\frac{1}{\rho U^{2}} \frac{D}{W}
$$

where by definition

$$
\mathrm{D}=\mathrm{W} \int_{0}^{x} \tau_{\mathrm{w}_{0}} \mathrm{dx}
$$

Hence

$$
D=\rho U^{2} \theta W
$$

Finally from Equations [49] and [53]

$$
C_{f}=\frac{2 \theta}{x}
$$

The substitution of the relations for $C_{f}$ from [54] and for $R_{x}$ into the Schoenherr formula, [47], produces

$$
\left(\frac{\theta}{x}\right)^{\frac{1}{2}}=\frac{1}{4.13 \sqrt{2} \log _{10}\left(\frac{2 U \theta}{\nu}\right)}
$$

Differentiation with respect to $x$ gives

$$
\frac{\mathrm{d} \theta}{\mathrm{dx}}=\left(\frac{\theta}{\mathrm{x}}\right)^{\frac{1}{2}} \frac{1}{8.26 \sqrt{2}}\left[\frac{1}{\log _{10}\left(\frac{2 \mathrm{U} \theta}{\nu}\right)^{\frac{1}{2}}+\log _{10} \mathrm{e}}\right]
$$

Substituting for $\left(\frac{\theta}{\mathrm{x}}\right)^{\frac{1}{2}}$ from [55] and using [50] finaliy results in

$$
\frac{\tau_{\mathrm{W}_{0}}}{\rho \mathrm{U}^{2}}=\frac{0.01466}{\log _{10}\left(2 \mathrm{R}_{\theta}\right)\left[\frac{1}{2} \log _{10}\left(2 \mathrm{R}_{\theta}\right)+0.4343\right]}
$$


With the exception of Falkner's equation, all the local-skinfriction formulas discussed in this section are plotted together in Figure 10 for comparison. It is seen that there are no appreciable numerical differences among them. For convenient reference the flat-plate formulas are listed in Table 2.

\section{TABLE 2}

Summary of Formulas for Local-Skin-Friction Coefficients of Flat Plates

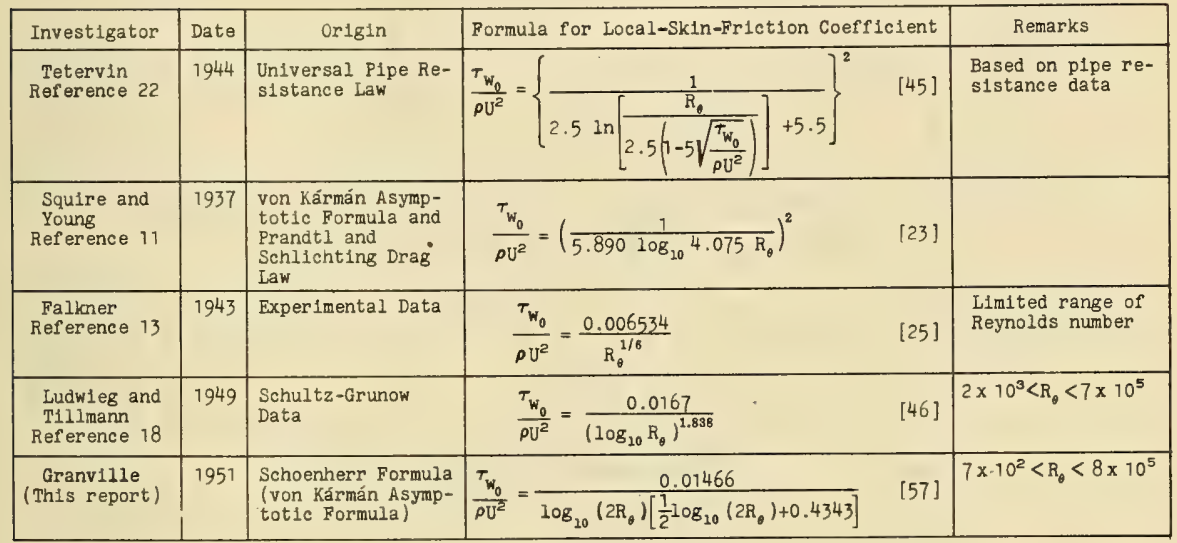

In addition to the local-skin-friction coefficient, the variation of the shape parameter of the velocity profiles $H_{0}$ of flat plates with Reynolds number at zero pressure gradient, is required in Equation [40] to evaluate the local-skin-friction coefficient in a pressure gradient. From the measurements of Schultz-Grunow, ${ }^{23}$ and from unpublished British data, Tetervin and Lin ${ }^{15}$ formulated the following empirical expression

$$
\log _{10} H_{0}=0.5990-0.1980 \log _{10} R_{\theta}+0.0189\left(\log _{10} R_{\theta}\right)^{2}
$$

for $1.5 \times 10^{3}<R_{\theta}<1 \times 10^{5}$. Figure 11, where Equation [58] 1s plotted, shows the decrease in $\mathrm{H}_{0}$ with increasing Reynolds number $R_{\theta}$. 


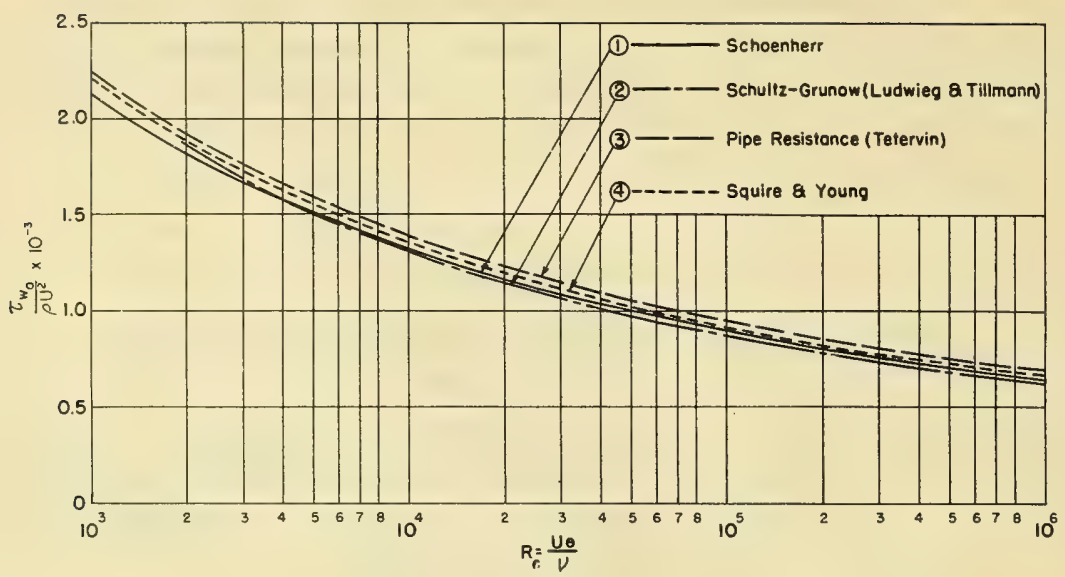

Figure 10 - Local-Skin-Friction Coefficient $\tau_{\mathrm{w}_{0}} / \mathrm{\rho} \mathrm{U}^{2}$ as Function of Local Reynolds Number $R_{\theta}$ for a Flat Plate

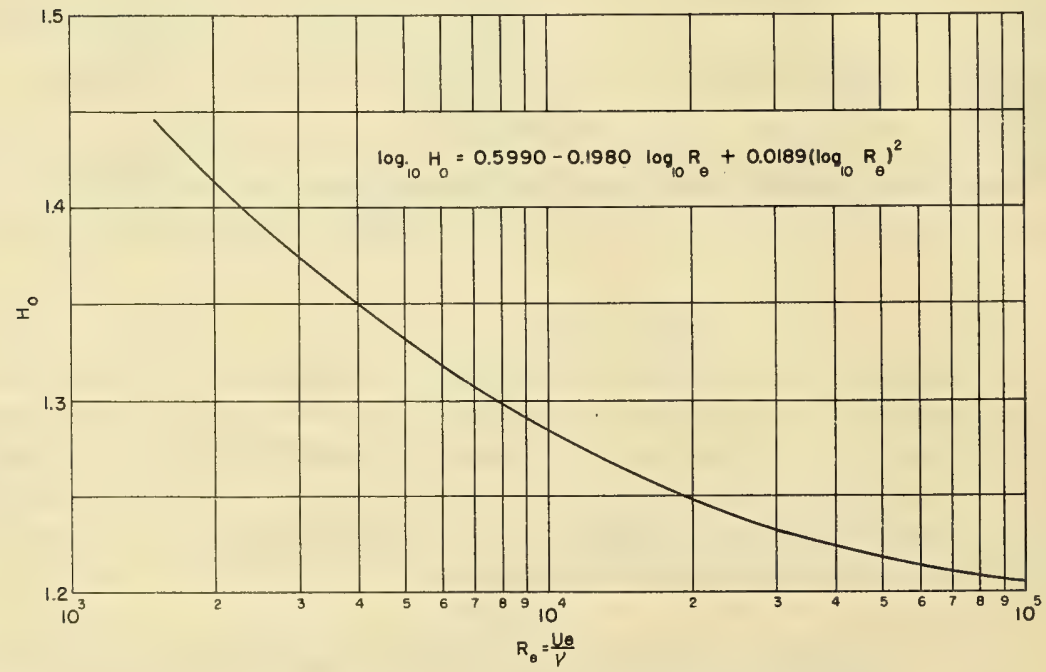

Figure 11 - Variation of Shape Parameter $H_{0}$ with Local Reynolds Number $R_{\theta}$ for Flat Plates (Tetervin and Lin, Reference 15) 
- INTEGRAL OF THE SHEARING-STRESS DISTRIBUTION

ACROSS THE BOUNDARY LAYER

In order for the moment-of-momentum equation [27] to be used numerically a relationship is required which describes the effect of pressure gradients on the integral of the shearing-stress distribution across the boundary layer $\int_{0}^{\delta} \frac{\tau}{\rho U^{2}} \mathrm{~d}\left(\frac{\mathrm{y}}{\delta}\right)$. Although almost no study, either theoretical or empirical, has been made of the integral of the shearing-stress distribution, some studies have been made of the shearing-stress distribution itself.

The hot-wire measurements of Schubauer and Klebanoff, ${ }^{25}$ shown in Figure 12, demonstrate the large changes produced in the shape of the shearingstress profile by an adverse pressure gradient. The shearing-stress curves have a positive slope at the wall determined by the positive pressure gradient; they then come to a peak, and finally drop to zero at the outer edge of the boundary layer. Several attempts have been made to derive analytical expressions for the general shearing-stress distribution; these are described below.

Fediaevsky, ${ }^{26}$ following the Pohlhausen method for laminar flow, tried to fit a polynomial expression for the shearing-stress distribution that would satisfy the boundary conditions at the inner and outer edges of the boundary layer. The coefficients $A_{j}$ of the following polynomial are to be evaluated:

$$
\frac{\tau}{\tau_{W}}=\sum_{j=0}^{l} A_{j}\left(\frac{y}{\delta}\right)^{j}
$$

The boundary conditions imposed by Fediaevsky are:
a. At $y=0, \quad \frac{\tau}{\tau_{\mathrm{w}}}=1 \quad$ by definition,
b. At $y=0, \quad \frac{\partial \tau}{\partial y}=\frac{d p}{d x} \quad \begin{aligned} & \text { from the boundary-layer } \\ & \text { equation, Equation [1], }\end{aligned}$
c. At $\mathrm{y}=\boldsymbol{\delta}, \quad \tau=0$ from the definition of boundary-layer thickness,
d. At $y=\delta, \quad \frac{\partial T}{\partial y}=0$
from the assumption that the derivative of the total head of the outer streamine is continuous,
e. At $y=0, \quad \frac{\partial^{2} \tau}{\partial y^{2}}=0$
from the derivative of the boundary-layer equation, Equation [1] and $\partial \mathrm{p} / \partial \mathrm{y}=0$. 
Substituting only the first three bolindary conditions $a, b$, and $c$ into Equation [59] and its derivatives to form a system of simultaneous equations for evaluating the coefficients, results in the following quadratic equation for the shearing-stress distribution

$$
\frac{\tau}{\tau_{W}}=1+\alpha\left(\frac{\mathrm{y}}{\delta}\right)-(1+\alpha)\left(\frac{\mathrm{y}}{\delta}\right)^{2}
$$

where $\alpha=\frac{\delta}{T_{w}} \frac{d p}{d x}$, a pressure-gradient parameter. Using all five boundary conditions yields the following quadratic equation for the shearing-stress distribution

$$
\frac{\tau}{\tau_{\mathrm{W}}}=1+\alpha\left(\frac{\mathrm{y}}{\delta}\right)-(4+3 \alpha)\left(\frac{\mathrm{y}}{\delta}\right)^{3}+(3+2 \alpha)\left(\frac{\mathrm{y}}{\delta}\right)^{4}
$$

Schubauer and Klebanoff ${ }^{25}$ found indifferent correlation between their exper1mental results and either of Fediaevsky's equations. Agreement is good at the

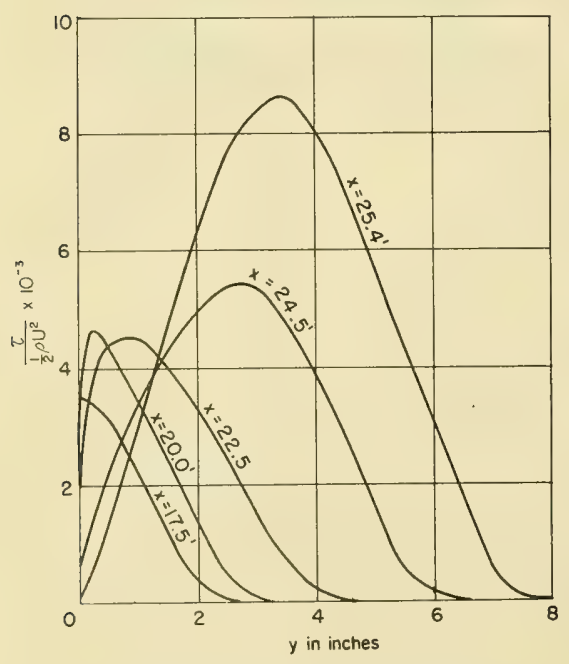

Figure 12 - Shearing-Stress Distributions in an Adverse Pressure Gradient as Measured by Schubauer and Klebanoff, Reference 25, At Various Stations beginning of the adverse pressure gradient and near the point of separation but is extremely poor at the intermediate stations.

In an attempt to improve on the Fediaevsky formulations, Ross and Robertson ${ }^{27}$ considered the shearingstress distribution to depend on its previous history of development along the boundary layer. Fediaevsky's boundary condition $(d)$ is altered to $\frac{\partial \tau}{\partial y}=-\frac{T_{W_{i}}}{\delta_{i}}$ at $\mathrm{y}=\delta$, in order to obtain a constant slope at the outer edge of the boundary layer travelling downstream from 1 , the initial position of the adverse pressure gradient. This requirement makes the shearing-stress distribution depend on conditions upstream. Using a modifled polynomial expression for $\tau$ and incorporating the revised boundary condition (d), together with the other four Fedlaevsky conditions, Ross and Robertson derived the following expression: 


$$
\frac{\tau}{\tau_{\mathrm{W}}}=\beta\left(1-\frac{\mathrm{y}}{\delta}\right)-(\alpha+\beta)\left(1-\frac{\mathrm{y}}{\delta}\right)^{q}+(\alpha+1)\left(1-\frac{\mathrm{y}}{\delta}\right)^{q+1}
$$

where

$$
q=\frac{2 \alpha+\beta+1}{\beta-1}
$$

and

$$
\boldsymbol{\beta}=\frac{{ }_{\mathrm{W}_{i}}}{{ }_{\mathrm{T}_{\mathrm{W}}}} \frac{\delta}{\delta_{i}}
$$

A comparison of the above expression with the experimental findings of Schubauer and Klebanoff shows a somewhat better agreement than the Fediaevsky relations.

The integral of the shearing-stress distribution will now be studied by integrating the analytic relations just described for the shearing-stress distribution and by analyzing the test data of Schubauer and Klebanoff. Let

$$
I=\int_{0}^{1} \frac{T}{\tau_{W}} d\left(\frac{y}{\delta}\right)
$$

By elementary integration the following expressions are derived: For the Fediaevsky 3-condition polynomial, Equation [60],

$$
I=0.67+0.17 \alpha
$$

for the Fediaevsky 5-condition polynomial, Equation [61],

$$
I=0.60+0.15 \alpha
$$

and for the Ross and Robertson equation, Equation [62]

$$
I=\frac{1}{2}\left(\frac{2 \alpha \beta+5 \beta-3}{2 \alpha+3 \beta-1}\right)
$$

Significant results are obtained from the data of Schubauer and Klebanoff when the integral of the shearing-stress distribution is nondimensionalized as follows

$$
\psi=\int_{0}^{\delta / \delta^{*}} \frac{\tau}{\rho \mathrm{U}^{2}} \mathrm{~d}\left(\frac{\mathrm{y}}{\delta^{*}}\right)
$$

or

$$
\psi=\left(\frac{T}{\rho U^{2}}\right)\left(\frac{\delta}{\delta^{*}}\right) I
$$


Values of $\psi$ are computed directly from the measurements of schubauer and Klebanuff by substituting data into Equation [67] and performing the indicated integrations numerically by Simpson's rule. For comparison, values of $\psi$ are obtained from the analytical formulations of I based on the methods of Fediaevsky and of Ross and Robertson by inserting values of $\alpha$ and $\beta$ from the experimental data into Equations [64], [65], and [66]. As seen in Figure 13, in which $\psi$ is plotted for various stations along the boundary layer, both of the Fediaevsky formulations show poor correlation with experimental points while the Ross and Robertson formulation shows only fair agreement. It is observed that except for experimental error the value of $\psi$ is practically constant for different stations along the boundary layer. This suggests that using a value of $\psi$ independent of the effects of pressure gradient ought to be sufficiently accurate for most technical problems encountered.

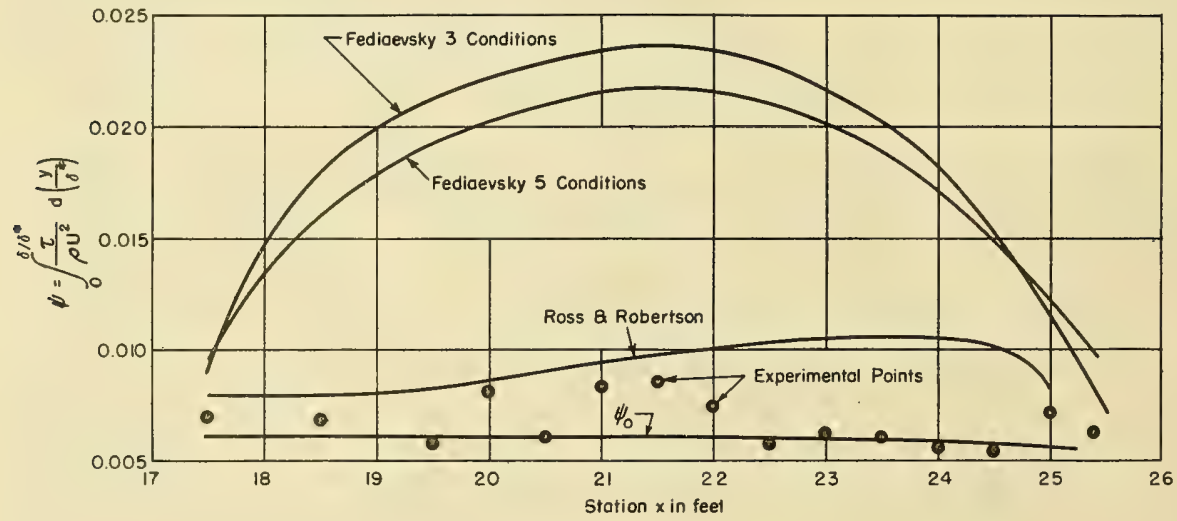

Figure 13 - Integral of Shearing Stresses Across the Boundary Layer for Data of Schubauer and Klebanoff, Reference 25

Before deciding on values of $\psi$ for pressure gradients in general, it will prove fruitful to investigate the values of $\psi$ in a zero pressure gradient. From Equation [68] $\psi$ for a zero pressure gradient or $\psi_{0}$ may be written as

$$
\psi_{0}=\frac{\tau_{W_{0}}}{\rho U^{2}} \frac{\delta_{0}}{\delta_{0}^{*}} I_{0}
$$


From [12], where a power law for the velocity profile is assumed,

$$
\frac{\delta_{0}}{\delta_{0}^{*}}=\frac{H_{0}+1}{H_{0}-1}
$$

Then

$$
\psi_{0}=\left(\frac{{ }^{\top}}{\rho \mathrm{U}_{0}}\right)\left(\frac{\mathrm{H}_{0}+1}{\mathrm{H}_{0}-1}\right) \mathrm{I}_{0}
$$

The value of $I_{0}$ is now derived analytically from the momentum and from the moment-of-momentum equations for flat plates with zero pressure gradient $\left(\frac{d U}{d x}=0\right)$ in the following manner. The moment-of-momentum equation, [27], reduces to

$$
\theta \frac{\mathrm{dH}_{0}}{\mathrm{dx}}=\left(H_{0}^{2}-1\right)\left[H_{0}-\left(H_{0}+1\right) I_{0}\right]_{\rho \mathrm{U}^{2}}^{T}
$$

and the momentum equation to

$$
\frac{\mathrm{d} \theta}{\mathrm{dx}}=\frac{\tau_{\mathrm{w}_{0}}}{\rho \mathrm{U}^{2}}
$$

Combining both equations gives

$$
\theta \frac{d H_{0}}{d x}=\left(H_{0}^{2}-1\right)\left[H_{0}-\left(H_{0}+1\right) I_{0}\right] \frac{d \theta}{d x}
$$

or

$$
\frac{\mathrm{d} H_{0}}{\mathrm{~d} \theta}=\frac{\left(\mathrm{H}_{0}^{2}-1\right)\left[\mathrm{H}_{0}-\left(\mathrm{H}_{0}+1\right) \mathrm{I}_{0}\right]}{\theta}
$$

In terms of $R_{\theta}=\frac{U \theta}{\nu}$, [74] becomes

$$
\frac{\mathrm{dH}_{0}}{\mathrm{dR}_{\theta}}=\frac{\left(\mathrm{H}_{0}^{2}-1\right)\left[\mathrm{H}_{0}-\left(\mathrm{H}_{0}+1\right) I_{0}\right]}{\mathrm{R}_{\theta}}
$$

Differentiation of the empirical equation of $H_{0}$, Equation [58], with respect to $R_{\theta}$ produces

$$
\frac{d H_{0}}{d R_{\theta}}=\frac{\left(-0.1980+0.0378 \log _{10} R_{\theta}\right) H_{0}}{R_{\theta}}
$$


Finally $I_{0}$ is evaluated by equating [75] and [76]. Then

$$
I_{0}=\frac{H_{0}}{H_{0}+1}\left[1+\frac{0.1980-0.0378 \log _{10} R_{\theta}}{H_{0}^{2}-1}\right]
$$

$R_{\theta}$ may be eliminated by use of Equation [58] to give

$$
I_{0}=\frac{H_{0}}{H_{0}+1}\left[1+\frac{0.0378 \sqrt{52.9 \log _{10} H_{0}-4.18}}{H_{0}^{2}-1}\right]
$$

The small variation of $I_{0}$ with Reynolds number $R_{\theta}$ is shown in Figure 14. For instance, at $R_{\theta}=1500, I_{0}=0.633$ and at $R_{\theta}=100,000, I_{0}=0.554$. These values appear reasonable when compared with those based or the Fediaevsky formulations: From Equation [64] for three conditions $I_{0}=0.67(\alpha=0$ for zero pressure gradient) and from Equation [65] for five conditions $I_{0}=0.60$.

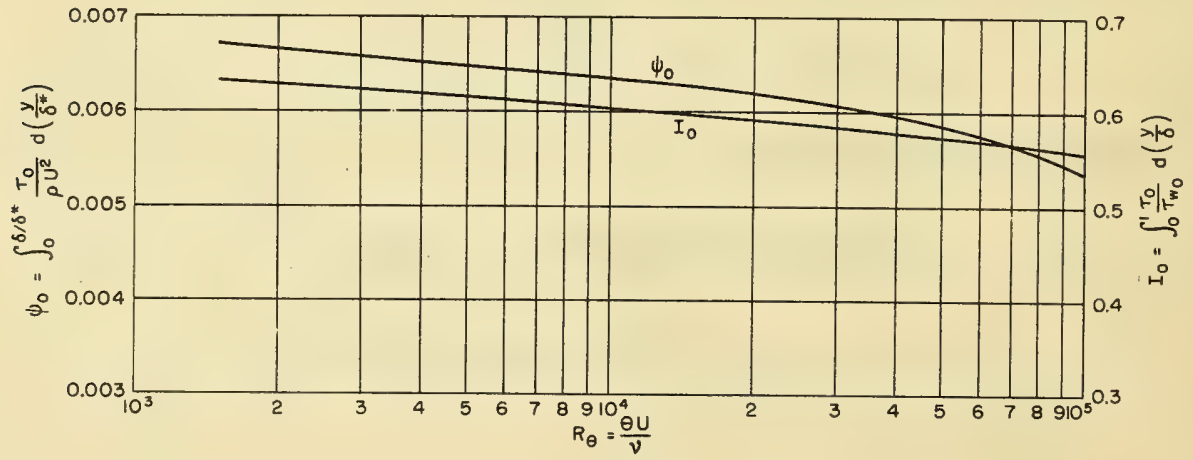

Figure 14 - Variation of Integral of Shearing Stresses across Boundary Layer with Reynolds Number $R_{\theta}$ for Flat Plates

Finally from Equations [71] and [78], $\psi_{0}$ is written

$$
\psi_{0}=\left(\frac{T_{0}}{\rho U^{2}}\right)\left(\frac{H_{0}}{H_{0}-1}\right)\left[1+\frac{0.0378 \sqrt{52.9 \log _{10} H_{0}-4.18}}{H_{0}^{2}-1}\right]
$$

Using the value of $\tau_{W_{0}} / \rho U^{2}$ from [57], derived from the Schoenherr formula, and the value of $\mathrm{H}_{0}$ from [58], the variation of $\psi_{0}$ with Reynolds number is shown graphically in Figure 14 . It is seen that $\psi_{0}$ diminishes gradually with Reynolds number. 
When the values of $\psi_{0}$, based on the same Reynolds number as those appearing in the experiments of Schubauer and Klebanoff, are plotted in Figure 13 for comparison, they produce a curve of almost constant value which is in excellent agreement with the experimental points of $\psi$. Based on this evidence It will be reasonable to conclude that at the same Reynolds number $\psi_{0}$ is a close approximation to $\psi$ for other boundary layers in pressure gradients similar to the boundary layer of Schubauer and Klebanoff. Further substantiation depends on additional experimentation, especially at high Reynolds numbers.

The integral of the shearing-stress distribution as required by the moment-of-momentum equation, Equation [27], is expressed in terms of $\psi$ as follows:

$$
\int_{0}^{1} \frac{\tau}{\rho \mathrm{U}^{2}} \mathrm{~d}\left(\frac{\mathrm{y}}{\delta}\right)=\frac{\delta^{*}}{\delta} \int_{0}^{\delta / \delta^{*}} \frac{\tau}{\rho \mathrm{U}^{2}} \mathrm{~d}\left(\frac{\mathrm{y}}{\delta}\right)=\frac{\delta^{*}}{\delta} \psi
$$

For power-law velocity profiles

$$
\frac{\delta^{*}}{\delta}=\frac{H-1}{H+1}
$$

and with the assumption $\psi=\psi_{0}$, where $\psi_{0}$ is defined in Equation [71], the integral of the shearing-stress distribution finally becomes

$$
\int_{0}^{1} \frac{\tau}{\rho U^{2}} d\left(\frac{y}{\delta}\right)=\left(\frac{H-1}{H+1}\right)\left(\frac{H_{0}+1}{H_{0}-1}\right)\left(\frac{\tau_{w_{0}}}{\rho U^{2}}\right) I_{0}
$$

This completes the shearing-stress relations required for transforming the moment-of-momentum equation into an auxiliary equation for characterlzing the shape of the velocity profiles.

\section{MODIFIED MOMENTUM AND MOMENT-OF-MOMENTUM EQUATIONS}

The substitution of the relation for local skin friction in a pressure gradient, Equation [40], into the von Kármán momentum equations, [6a] and [6b], modifies them as follows: For two-dimensional flows,

$$
\frac{\mathrm{d} \theta}{\mathrm{dx}}=-(\mathrm{H}+2) \frac{\theta}{\mathrm{U}} \frac{\mathrm{dU}}{\mathrm{dx}}+\left(\frac{\gamma}{\gamma_{0}}\right)^{\frac{4}{H_{0}+1}} \frac{\tau_{\mathrm{w}_{0}}}{\rho \mathrm{U}^{2}}
$$

and for axisymmetric flows (where $\delta \ll r_{w}$ ),

$$
\frac{d\left(r_{w} \theta\right)}{d x}=-(H+2) \frac{r_{w} \theta}{U} \frac{d U}{d x}+\left(\frac{\gamma}{\gamma_{0}}\right)^{\frac{4}{H_{0}+1}} r_{w} \frac{T_{w_{0}}}{\rho U^{2}}
$$


The insertion of the relations for local skin friction and for the integral of the shearing-stress distribution, [40] and [81], into the moment-ofmomentum equation [27], converts it into the following equation, which is applicable to the calculation of both two-dimensional and axisymmetric flows where $\left.\delta \ll r_{W}\right)$

$$
\theta \frac{\mathrm{dH}}{\mathrm{dx}}=-\frac{\mathrm{H}(H+1)\left(H^{2}-1\right)}{2} \frac{\theta}{\mathrm{U}} \frac{\mathrm{dU}}{\mathrm{dx}}+\left(H^{2}-1\right)\left[H\left(\frac{\gamma}{\gamma_{0}}\right)^{\frac{4}{H_{0}+1}}-(H-1) \frac{\left(H_{0}+1\right)}{\left(H_{0}-1\right)} I_{0}\right] \frac{\tau_{0}}{\rho U^{2}}
$$

where $\gamma, \gamma_{0}$ and $I_{0}$ are defined in Equations [42], [43], and [78] respectively, and the subscript 0 refers to flat-plate values at the same Reynolds number $R_{\theta}$. This equation is the desired auxiliary equation to be solved simultaneously with one of the modified von Kármán momentum equations, [82a] or [82b], for calculating the growth of boundary layers in pressure gradients.

The modified moment-of-momentum equation of this report represents an auxiliary equation whose form has a theoretical basis and whose coefficlents have been evaluated indirectly from flat-plate data. On the other hand the various auxiliary equations described in this report are almost wholly empirical in origin. A comparison of the auxiliary equations may be made by writing them in the following generalized form

$$
\theta \frac{d H}{d x}=-A\left(\frac{\theta}{U} \frac{d U}{d x}\right)-B
$$

The expression for the variation of $\eta$ in the Gruschwitz or Kehl method is converted into the above form by using the power-law formula, [15], for the relation between $\eta$ and $H$. The expressions for the coefficients, $A$ and $B$, are listed in Table 3 for the various auxiliary equations. It is seen that the coefficients for the Kehl, Garner and the moment-of-momentum equations are functionally similar with $A=f(H)$ and $B=f\left(H, R_{\theta}\right)$. The von Doenhoff and Tetervin equation, however, has the Reynolds-number effect in coefficient $A$ instead of coefficient $B$. As expected, none of the coefficients for the Gruschwitz method exhibits a Reynolds-number effect.

The coefficients $A$ and $B$ are plotted against $H$ in Figures 15, 16, and 17 for two different values of $R_{\theta}$. It is observed that although all the curves have the same general shape and trend, there are marked differences in the magnitude of the ordinates. The exponential form of the coefficients of the Garner and of the von Doenhoff and Tetervin equations is responsible for the very large increase in value of the coefficients at the higher values of $H$. The curves for the coefficients of the modifled moment-of-momentum equation of this report maintain average positions among the other curves. 


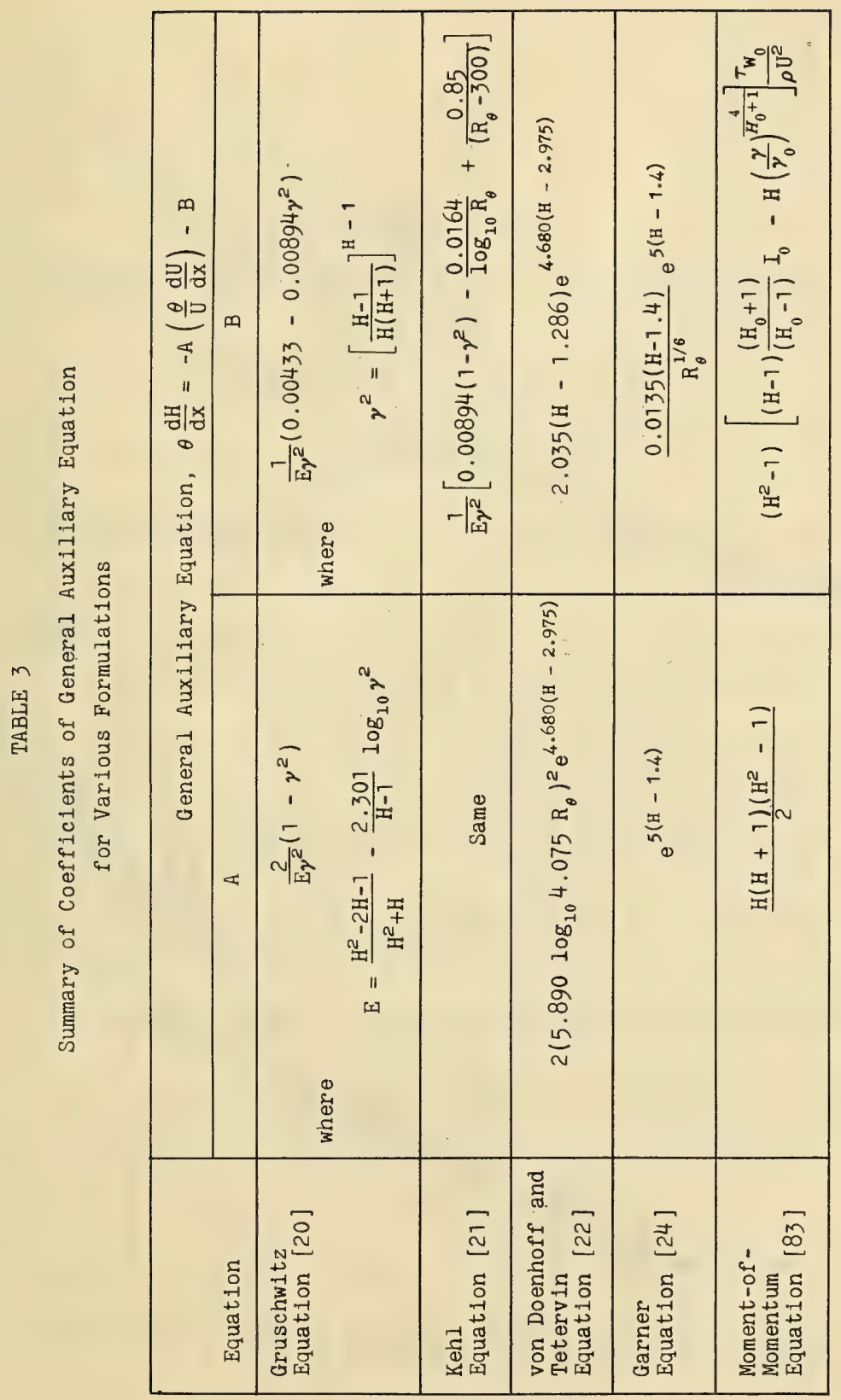



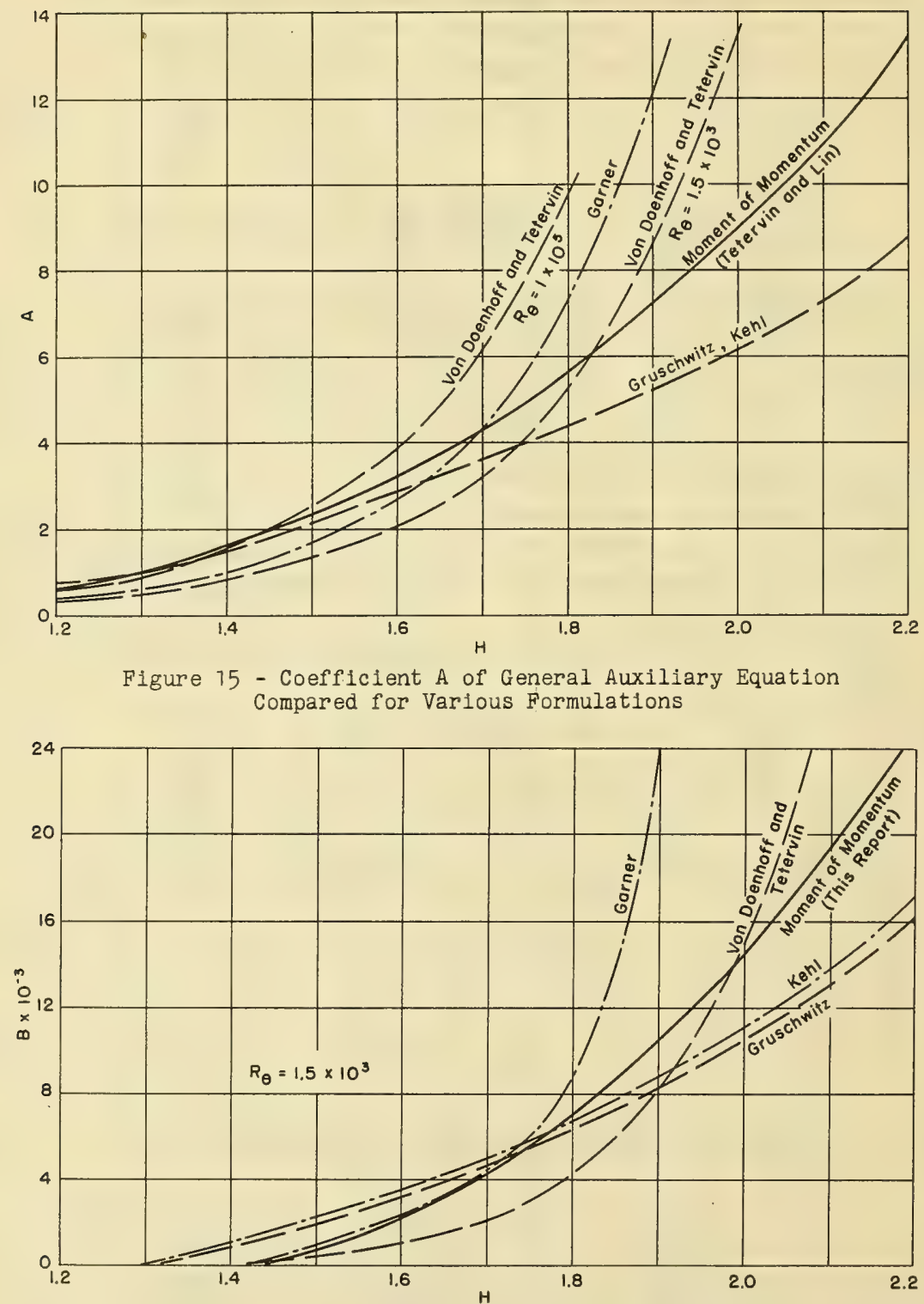

Figure 16 - Coefficient B of General Auxiliary Equation Compared for Various Formulations at Reynolds Number $R_{\theta}=1.5 \times 10^{3}$ 


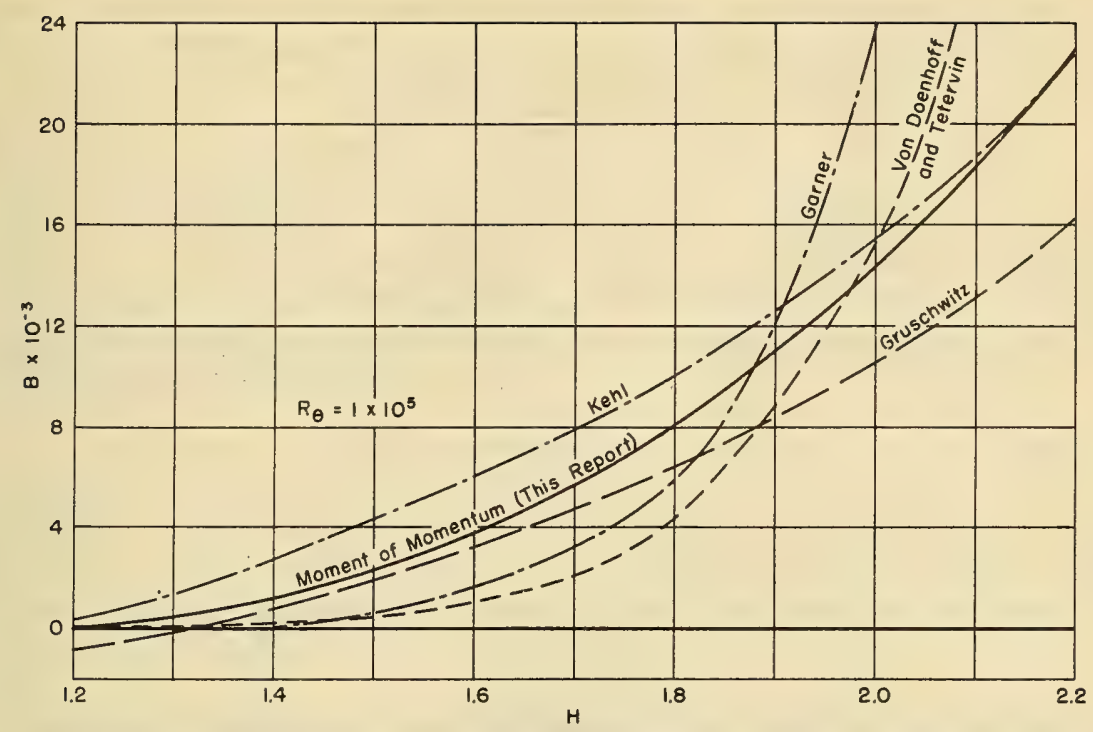

Figure 17 - Coefficient B of General Auxiliary Equation Compared for Various Formulations at Reynolds Number $R_{\theta}=1 \times 10^{5}$

Although this fact does not conclusively prove the validity of the modified moment-of-momentum equation, it does indicate that-as such-the modified moment-of-momentum equation has a proper range of values for an auxiliary equation giving the variation of $\mathrm{H}$. There is a need for a larger body of reliable measurements of turbulent boundary layers under a variety of conditions and for increased emphasis on measurements of the shearing stresses both at the surface and throughout the boundary layer.

\section{SUMMARY OF METHOD OF CALCULATING TURBULENT BOUNDARY LAYERS IN A PRESSURE GRADIENT}

For calculating turbulent boundary layers in a pressure gradient the following relations are involved: The momentum equation for two-dimensional flows,

$$
\frac{\mathrm{d} \theta}{\mathrm{dx}}=-(\mathrm{H}+2) \frac{\theta}{\mathrm{U}} \frac{\mathrm{dU}}{\mathrm{dx}}+\left(\frac{\gamma}{\gamma_{0}}\right)^{\frac{4}{H_{0}+1}} \frac{\tau_{\mathrm{w}_{0}}}{\rho \mathrm{U}^{2}}
$$


or the momentum equation for axisymmetric flow $\left(\delta<<r_{W}\right)$,

$$
\frac{\mathrm{d}\left(\mathrm{r}_{\mathrm{W}} \theta\right)}{\mathrm{dx}}=-(\mathrm{H}+2) \frac{r_{\mathrm{W}} \theta}{\mathrm{U}} \frac{d \mathrm{U}}{d x}+\left(\frac{\gamma}{\gamma_{0}}\right)^{\frac{4}{H_{0}+1}} r_{\mathrm{W}} \frac{\tau_{\mathrm{W}_{0}}}{\rho \mathrm{U}^{2}}
$$

and the moment-of-momentum equation which holds for both two-dimensional and axisymmetric flows $\left(\delta<\mathrm{r}_{\mathrm{w}}\right)$,

$$
\theta \frac{\mathrm{dH}}{\mathrm{dx}}=-\frac{\mathrm{H}(\mathrm{H}+1)\left(\mathrm{H}^{2}-1\right)}{2} \frac{\theta}{\mathrm{U}} \frac{\mathrm{dU}}{\mathrm{dx}}+\left(\mathrm{H}^{2}-1\right)\left[H\left(\frac{\gamma}{\gamma_{0}}\right)^{\frac{4}{H_{0}+1}}-(H-1) \frac{\left(H_{0}+1\right)}{\left(\mathrm{H}_{0}-1\right)} I_{0}\right] \frac{\tau_{\mathrm{w}_{0}}}{\rho \mathrm{U}^{2}}
$$

where

$$
\gamma=\left[\frac{H-1}{H(H+1)}\right]^{\frac{H-1}{2}}
$$

and

$$
\gamma_{0}=\left[\frac{H_{0}-1}{H_{0}\left(H_{0}+1\right)}\right]^{\frac{H_{0}-1}{2}}
$$

The variation of $\left(\gamma / \gamma_{0}\right) \frac{4}{H_{0}+1}$ with $H$ and $H_{0}$ is shown in Figure 9 . The variation of $H_{0}$ with $R_{\theta}$, shown in Figure 11 , is given by Reference 15 as

$$
\log _{10} H_{0}=0.5990-0.1980 \log _{10} R_{\theta}+0.0189\left(\log _{10} R_{\theta}\right)^{2}
$$

The relation between $I_{0}$ and $H_{0}$ is

$$
I_{0}=\frac{H_{0}}{H_{0}+1}\left[1+\frac{0.0378 \sqrt{52.9 \log _{10} H_{0}-4.18}}{H_{0}^{2}-1}\right]
$$

Figure 14 shows $I_{0}$ as a function of $R_{\theta}$. The variation of $\tau_{w_{0}} / \rho U^{2}$ with $R_{\theta}$, Figure 10, for the Schoenherr formula is

$$
\frac{\tau_{W_{0}}}{\rho U^{2}}=\frac{0.01466}{\log _{10}\left(2 R_{\theta}\right)\left[\frac{1}{2} \log _{10}\left(2 R_{\theta}\right)+0.4343\right]}
$$

The variation of $U$ and $d U / d x$ with $x$ will be specified for a particular problem and may be obtained either by pressure measurements or potential-flow calculations.

The momentum and moment-of-momentum equations are solved for $\theta(x)$ and $H(x)$ as a pair of simultaneous differential equations, usually by numerical methods involving step-wise integration. The initial conditions for $\theta(x)$ and $H(x)$ are imposed by the physical conditions of the problem such as the 
transition point from laminar to turbulent flow. It is customary to use the value of $\theta$ of the laminar boundary layer at the transition point as the initial value of $\theta$ for the turbulent boundary layer. Owing to the lack of rellable data on transition, the initial value of $H$ may be taken as that for a flat plate at the same Reynolds number $R_{\theta}$.

The evaluation of $\theta$ and $H$ is required in many technical hydrodynamic and aerodynamic applications involving calculations of drag and of velocity profiles of boundary layers. According to the following formula of Squire and Young ${ }^{11}$ for the profile drag of airfoils, $\theta$ and $H$ must be determined at the trailing edge

$$
\mathrm{D}=\rho \mathrm{U}_{\infty}^{2} \theta_{t}\left(\frac{\mathrm{U}_{t}}{\mathrm{U}_{\infty}}\right)^{\frac{H_{t}+5}{2}}
$$

where the subscript $t$ refers to conditions at the trailing edge. If a powerlaw distribution is assumed, the values of $\theta$ and $H$ at any station along the boundary layer specify the shape and thickness of the velocity profile, as shown by Equation [16],

$$
\frac{u}{U}=\left[\left(\frac{y}{\theta}\right) \frac{(H-1)}{H(H+1)}\right]^{\frac{H-1}{2}}
$$

A knowledge of the characteristics of the velocity profiles of boundary layers is required for the design of control surfaces and propellers on forms moving in fluids and of the various conduit sections of water and wind tunnels. Large values of $\mathrm{H}$ indicate the danger of flow separation for cases involving adverse pressure gradients.

\section{ACKNOWLEDGMENTS}

The author wishes to express his thanks to Mr. M.P. Tulin, Dr. A. Borden and Mr. P. Eisenberg for their critical review of this report. The general form for the auxiliary equation, Equation [84], was suggested by Mr. Tulin. 


\section{REFERENCES}

1. Prandt1, L., "The Mechanics of Viscous Fluids," vol. III, Aerodynamic Theory, W.F. Durand, ed., Julius Springer (Berlin), 1935.

2. Goldstein, S., ed., "Modern Developments in Fluid Dynamics," Clarendon Press (Oxford), 1938.

3. Schlichting, H., "Boundary Layer Theory, Part 2 - Turbulent Flows", NACA TM 1218, April 1949 (Translation of lectures given 1941/43 at the Luftfahrtforschunganstalt Hermann Goering, Braunschweig).

4. Ross, D., and Robertson, J.M., "Water Tunnel Diffuser Flow Studies, Part 1 - Review of Literature," Ordnance Research Laboratory (Pennsylvania State College) Report 7958-139, May 1949.

5. Gruschwitz, E., "Die turbulente Reibungsschicht in ebener Strömung bei Druckabfall und Druckanstieg," (The turbulent boundary layer in plane flow with pressure rise and fall) Ingenieur-Archiv, vol. II, No. 3, September 1931, pp. $321-346$.

6. Kehl, A., "Investigations of Convergent and Divergent Turbulent Boundary Layers," (British) Ministry of Aircraft Production R.T.P. Translation 2035 (From Ingenieur-Archiv, vol. XIII, No. 5, 1943, pp. 293 to 329).

7. von Doenhoff, A.E., and Tetervin, N., "Determination of General Relations for the Behavior of Turbulent Boundary Layers, "NACA Report 772 , 1943.

8. Pretsch, J., "Theoretical Solution of Profile Drag," NACA TM 1009, April 1942 (Translation from Jahrbuch 1938 der deutschen Lufteahrtforschung).

9. Buri, A., "A Method of Calculation for the Turbulent Boundary Layer with Accelerated and Retarded Basic Flow," (British) Ministry of Aircraft Production R.T.P. Translation 2073 (From Thesis 652, Federal Technical College, Zurich, 1931).

10. Howarth, L., "Lift Coefficient for a Thin Elliptic Cylinder," Proceedings of the Royal Soclety, A., (London), vol. 149, 1935, pp. 558-586.

11. Squire, H.B., and Young, A.D., "The Calculation of the Profile Drag of Aerofoils," (British) Aeronautical Research Committee R \& M 1838, November 1937.

12. Garner, H.E., "The Development of Turbulent Boundary Layers," (British) Aeronautical Research Council R \& M 2133, June 1944.

13. Falkner, V.M., "The Resistance of a Smooth Flat Plate with Turbulent Boundary Layer," Aircraft Engineering, vol. XV, No. 169, March 1943. 
14. Coleman, W.S., "Analysis of the Turbulent Boundary Layer for Adverse Pressure Gradients Involving Separation," Quarterly of Applied Mathematics, vol. V, No. 2, July 1947.

15. Tetervin, N. and Lin, C.C., "A General Integral Form of the BoundaryLayer Equation for Incompressible Flow with an Application to the Calculation of the Separation Point of Turbulent Boundary Layers, "NACA TN 2158, August 1950.

16. Peters, H., "On the Separation of Turbulent Boundary Layers," Journal of the Aeronautical Sciences, vol. 3, No. 1, September 1935, pp. 7-12.

17. Fage, A., and Raymer, W.G., "Note on Empirical Relations for a Turbulent Boundary Layer," (British) Aeronautical Research Council R \& M 2255 , March 1946.

18. Ludwieg, H., and Tillmann, W., "Investigations of Surface Shearing Stresses in Turbulent Boundary Layers," NACA TM 1285, May 1950 (Translation from Ingenieur-Archiv, vol. 17, No. 4, 1949, p. 288).

19. Ludwieg, H., "Instrument for Measuring the Wall Shearing Stress of Turbulent Boundary Layers," NACA TM 1284, May 1950 (Translation from IngenieurArchiv, vol. 17, 1949, p. 207).

20. Wieghardt, K., "Turbulent Boundary Layers," (British) Ministry of Supply, VG R \& T 1006 (Translation of AVA Monographs, MAP VG 306) April 1948.

21. Landweber, L., "A Review of the Theory of the Frictional Resistance of a Smooth Flat Plate with Turbulent Boundary Layers," in "Progress Report on Research in Frictional Resistance," TMB Report 726, September 1950.

22. Tetervin, N., "A Method for the Rapid Estimation of Turbulent Boundary-Layer Thickness for Calculating Profile Drag," NACA Wartime Report L-16, July 1944 .

23. Schultz-Grunow, F., "New Frictional Resistance Law for Smooth Plates," NACA TM 986, 1941 (Translation from Luftfahrtforschung vol. 17, No. $8,1940)$.

24. Schoenherr, K.E., "Resistance of Flat Surfaces Moving Through a Fluid," Transactions of the Society of Naval Architects and Marine Engineers, 1932 .

25. Schubauer, G.B., and Klebanoff, P.S., "Investigation of Separation of the Turbulent Boundary Layer," NACA TN 2133, August 1950. 
26. Fediaevsky, K., "Turbulent Boundary Layer of an Airfo11," NACA TM 822, April 1937 (Translation from Report 282 of Central Aero-Hydrodynamical Institute, Moscow, 1936).

27. Ross, D., and Robertson, J.M., "Shear Stress in a Turbulent Boundary Layer," Journal of Applied Physics, vol. 21, No. 6, June 1950. 
